NBER WORKING PAPER SERIES

\title{
GROSS WORKER FLOWS AND FLUCTUATIONS IN \\ THE AGGREGATE LABOR MARKET
}

\author{
Per Krusell \\ Toshihiko Mukoyama \\ Richard Rogerson \\ Ayşegül Şahin \\ Working Paper 26878 \\ http://www.nber.org/papers/w26878 \\ NATIONAL BUREAU OF ECONOMIC RESEARCH \\ 1050 Massachusetts Avenue \\ Cambridge, MA 02138 \\ March 2020
}

This paper is written for a special issue of the Review of Economic Dynamics commemorating the 25th anniversary of the 1995 Cooley volume entitled Frontiers of Business Cycle Research. We thank Mark Bils, Jonathan Heathcote, Vincenzo Quadrini, and the conference participants at the Frontiers of Business Cycle Research Conference for helpful comments. All errors are ours. Corresponding author: Richard Rogerson, Woodrow Wilson School, Princeton University, Princeton, NJ 08544; 609-258-4839, rdr@princeton.edu The views expressed herein are those of the authors and do not necessarily reflect the views of the National Bureau of Economic Research.

At least one co-author has disclosed a financial relationship of potential relevance for this research. Further information is available online at http://www.nber.org/papers/w26878.ack

NBER working papers are circulated for discussion and comment purposes. They have not been peer-reviewed or been subject to the review by the NBER Board of Directors that accompanies official NBER publications.

(C) 2020 by Per Krusell, Toshihiko Mukoyama, Richard Rogerson, and Ayşegül Şahin. All rights reserved. Short sections of text, not to exceed two paragraphs, may be quoted without explicit permission provided that full credit, including $\odot$ notice, is given to the source. 
Gross Worker Flows and Fluctuations in the Aggregate Labor Market

Per Krusell, Toshihiko Mukoyama, Richard Rogerson, and Ayşegül Şahin

NBER Working Paper No. 26878

March 2020

JEL No. E24,E32,J22,J64

\section{ABSTRACT}

We build a three-state general equilibrium model of the aggregate labor market that features both standard labor supply forces and labor market frictions. Our model matches key features of the cyclical properties of employment, unemployment, and nonparticipation as well as those of gross worker flows across these three labor market states. Our key finding is that shocks to labor market frictions play a dominant role in accounting for labor market fluctuations. This is in contrast to the focus of the traditional RBC literature, which emphasized how employment fluctuations arise as a consequence of labor supply responses to price changes induced by TFP shocks.

Per Krusell

Institute for International Economic Studies

Stockholm University

10691 STOCKHOLM

SWEDEN

and NBER

per.krusell@iies.su.se

Toshihiko Mukoyama

Department of Economics

Gerogetown University

37th and O Streets, N.W.

Washington D.C. 20057-1036

tm1309@georgetown.edu
Richard Rogerson

Department of Economics

JRR Building Room 292

Princeton University

Princeton, NJ 08544

and NBER

rdr@princeton.edu

Ayşegül Şahin

Department of Economics

University of Texas at Austin

2225 Speedway

Austin, TX 78712

and NBER

aysegul.sahin@austin.utexas.edu 


\section{Introduction}

The Frontiers of Business Cycle Research volume (Cooley, 1995) synthesized a body of frontier research that ushered in a new era in business cycle research. The research agenda that it laid out had several defining characteristics. One was the insistence on general equilibrium. A second was the insistence on micro-foundations, i.e., an explicit delineation of which parameters were primitives of preferences and technology and hence invariant to policy. The third was the insistence on studying business cycle fluctuations as deviations from trend growth. All three of these criteria remain strongly reflected in business cycle research today.

But the Cooley volume was not just about the methodology of studying business cycles; it also employed this methodology to address substantive issues. Given that labor market fluctuations have been a long-standing focus within the business cycle literature, it is not surprising that several of the chapters in the Cooley volume focused on aspects of labor market fluctuations. The goal was simple: heeding the three "axioms" described above, to deliver a version of the growth model that could account for the magnitude of employment fluctuations.

Our goal in this paper is to offer an updated perspective on modelling labor market fluctuations. The need for an update reflects two important developments since the writing of the Cooley volume, one methodological and one substantive.

A key methodological development in macroeconomic research more broadly over the last twenty-five years concerns the threshold for what it means for a model to have adequate micro foundations. Recent research in almost all areas of macroeconomic stresses the desire to build models that can not only address aggregate time series, but also the rich cross-sectional and panel variation found in large micro data sets. ${ }^{1}$ This trend is witnessed in studies that focus

\footnotetext{
${ }^{1}$ As Krueger et al. (2010) wrote in their introduction to the special issue of the Review of Economic Dynam$i c s$, ". . restricting heterogeneous agent macro models so that the equilibrium distributions of hours worked, income, consumption and wealth line up well with their empirical counterparts is crucial for a convincing policy analysis."
} 
on aggregate consumption, aggregate investment, and price-setting. ${ }^{2}$

The second and substantively important change since the publication of the Cooley volume has been the development of general equilibrium models featuring labor market frictions. These allow us to rigorously connect theory with data on unemployment.

At the time of the Cooley volume, the leading account of labor market fluctuations was Hansen (1985). Notably, Hansen's model only distinguished between the employed and the non-employed; it made no attempt to distinguish the two different categories of nonemployment-unemployment and out of the labor force. And although his model featured individuals moving between employment and non-employment, it made no attempt to connect these flows to the flows in micro-data. Our goal in this paper is to understand aggregate movements in employment, unemployment, and non-participation, while at the same time accounting for the underlying movements of individuals between these three labor market states.

In the first part of this paper, we document the key features of the relevant data. In particular, we use the Current Population Survey (CPS) data to document both the average values for gross worker flows among labor market states as well the cyclical fluctuations in these gross flows.

The second part of the paper presents a version of the growth model with heterogeneous agents that in steady state matches both the aggregate distribution of workers across the three labor market states and the average flows of workers between these states. This model can be understood as bringing labor market frictions as modeled in the island economy of Lucas and Prescott (1974) into the heterogeneous agent-incomplete markets model of Chang and Kim (2006). The Lucas-Prescott formulation amounts to treating the frictions as exogenous; in the conclusion of our paper we emphasize that it would be valuable to study how the

\footnotetext{
${ }^{2}$ See for example, Kaplan and Violante (2014) for work on consumption, Thomas (2002) and Veracierto (2002) for investment, and Golosov and Lucas (2007) for prices.
} 
frictions are determined..$^{3}$

Having developed a model that can account for the behavior of gross worker flows in steady state, we then subject this economy to shocks to assess its implications for movements in both the levels of employment, unemployment, and non-participation and the movements in gross worker flows among these three states. Our first exercise is a traditional Real Business Cycle (RBC) exercise in which we consider aggregate shocks to Total Factor Productivity (TFP) as the sole aggregate shock. A striking result emerges: Even if TFP shocks are sufficiently large to generate employment fluctuations like those found in the data, they have strongly counterfactual predictions for not only for the movements in gross worker flows but also for movements in the aggregate stocks of unemployment and participation.

Our second exercise considers shocks to both aggregate TFP and the model parameters that characterize frictions in the labor market, which consist of three job-finding rates and a job-separation rate. Our main finding is that empirically reasonable values for shocks to these frictional parameters in addition to shocks to aggregate TFP provide a good account not only for the cyclical movements in employment, unemployment, and non-participation but also for the cyclical movements in gross worker flows.

A decomposition exercise shows that shocks to the frictional parameters play a dominant role. In the traditional RBC literature, employment fluctuations were generated as labor supply responses to TFP-induced changes in prices. In our model, this mechanism is present but plays a secondary role. This has important implications for our understanding of labor market fluctuations. If TFP shocks are the dominant primitive source of labor market fluctuations, it is essential to include a channel through which they impact labor market frictions. More generally, our analysis shows that understanding the movements in frictions is central to understanding labor market fluctuations.

Our analysis in this paper draws heavily on the material in Krusell et al. (2017). But

\footnotetext{
${ }^{3}$ Alvarez and Veracierto (2000) and Alvarez and Shimer (2011) also study the Lucas-Prescott island economy.
} 
importantly, whereas the analysis in Krusell et al. (2017) was partial equilibrium, taking all prices as constant over time, our analysis here is general equilibrium in the sense that we have prices responding endogenously to the aggregate shocks. ${ }^{4}$ These general-equilibrium interactions are quantitatively significant and have an important effect on our conclusions. Second, Krusell et al. (2017) did not study TFP shocks, which are an important part of the focus here. Third, to simplify exposition, the model studied here is somewhat simpler than the one in Krusell et al. (2017): it abstracts from the presence of the unemployment insurance (UI). While the presence of a UI system does have a small impact on some quantitative aspects of the model, modeling UI in an empirically reasonable way increases the size of the model's state space and our results here suggest that the quantitative effects are not of first order.

We also want to highlight the method that we use to solve for the business cycle properties of our model. Whereas previous papers in the heterogeneous agent business cycle literature have largely relied on the method of Krusell and Smith (1998), we compute business cycle properties by adopting the method developed by Boppart et al. (2018). This method delivers equilibria for models with aggregate shocks based on perfect-foresight equilibria given unexpected shocks away from steady state: so-called MIT shocks. The latter are straightforward to compute even in models that are highly nonlinear on the microeconomic level, hence allowing heterogeneous agent general equilibrium models with aggregate fluctuations to be coded up and solved rather handily. The benefit is particularly large for a relatively complex economy like ours. ${ }^{5}$ An important contribution of the original Cooley volume was to provide researchers with a tool-kit, and we think that (the application of) this new computational method is a valuable innovation in this regard.

Our analysis builds on four strands of literature. The first is a large literature on gross

\footnotetext{
${ }^{4}$ An earlier working paper version (Krusell et al., 2012) also contains general-equilibrium analysis, although there are various differences in the model setting.

${ }^{5}$ The general equilibrium model of Krusell et al. (2012) is computed by directly extending Krusell and Smith's (1998) computational method.
} 
worker flows. ${ }^{6}$ A second is the literature on individual labor supply in the presence of frictions. Ham (1982) rigorously considered unemployment in the context of optimal labor supply, and argued that unemployment spells should not be interpreted as a component of optimal labor supply responses. Our model is consistent with this finding; it features both an operative labor supply margin and unemployment, and unemployment in our model reflects a departure from desired labor supply. Low et al. (2010) is also concerned with labor supply in the presence of frictions. But whereas we focus on business cycle fluctuations, their analysis focused on life cycle variation.

A third strand is a recent literature that extends business cycle models of employment and unemployment to consider movements in participation. ${ }^{7}$ The key distinguishing feature of our analysis relative to these is that we study gross worker flows and not just labor market stocks.

The fourth strand of literature is heterogeneous agent models of aggregate labor supply, as in Krusell and Smith (1998, Appendix B) and Chang and Kim (2006). Our model contributes to this literature by introducing a labor market with realistic frictions.

An outline of the paper follows. In the next section we document the key business cycle facts for gross worker flows among the three labor market states for the US over the period 1978-2012. Section 3 describes our theoretical framework and Section 4 calibrates the model so that in steady state it matches both the distribution of workers across labor market states as well as the average flows of workers between states. Section 5 carries out our main business cycle exercises and shows that our model can account for the key facts laid out in Section 2. Section 6 presents the decomposition results to assess the relative importance of the three different shocks in our model. Section 7 documents the importance of general equilibrium

\footnotetext{
${ }^{6}$ This includes, for example, Abowd and Zellner (1985), Poterba and Summers (1986), Blanchard and Diamond (1990), Davis and Haltiwanger (1992), Fujita and Ramey (2009), Shimer (2012), and Elsby et al. (2015).

${ }^{7}$ These include Tripier (2004), Veracierto (2008), Christiano et al. (2010), Galí et al. (2011), Ebell (2011), Haefke and Reiter (2011), and Shimer (2013).
} 
effects. Section 8 concludes.

\section{Worker Flows over the Business Cycle}

In this section, we document the business-cycle facts for gross worker flows. The information reported in this section is reproduced from Krusell et al. (2017), and we refer the reader to that paper for more detail on the construction of the data and related details. Our data source is the monthly CPS microdata for the period 1978-2012. ${ }^{8}$

We let $E, U$, and $N$ denote the levels of employment, unemployment and not in the labor force, respectively, and let $Y$ denote the level of real GDP. We use $u$ to denote the unemployment rate $(U /(E+U))$ and lfpr to denote the labor-force participation rate $((E+$ $U) /(E+U+N))$. Table 1 presents summary statistics from the data for the business-cycle properties for the labor-market stocks. ${ }^{9}$

Table 1

\begin{tabular}{|c|c|c|c|}
\hline \multicolumn{4}{|c|}{ Cyclical Properties of Stocks: 1978Q1-2012Q3 } \\
\hline & $u$ & lfpr & $E$ \\
\hline $\operatorname{std}(x)$ & 0.1170 & 0.0026 & 0.0099 \\
\hline $\operatorname{corrcoef}(x, Y)$ & -0.84 & 0.21 & 0.83 \\
\hline $\operatorname{corrcoef}\left(x, x_{-1}\right)$ & 0.93 & 0.69 & 0.92 \\
\hline
\end{tabular}

Source: Krusell et al. (2017)

Table 1 confirms some well known facts: unemployment has the highest volatility and is strongly countercyclical; employment is the second most volatile and is strongly procyclical; and the labor force participation rate is the least volatile and is modestly procyclical. Note that because we measure percent deviations from trend, the much higher volatility of unemployment at least partly reflects the fact that the stock of unemployed workers is more than an order of magnitude smaller than the stock of employed workers. All three series are highly autocorrelated, but the participation rate displays the smallest autocorrelation. We

\footnotetext{
${ }^{8}$ We restrict attention to the period 1978Q1-2012Q3 since that is the period for which we have consistent data on adjusted gross flows.

${ }^{9}$ The cyclical components are isolated using an HP filter with the smoothing parameter of 1600, applied to quarterly averages of monthly data. In addition to Krusell et al. (2017), see Blanchard and Diamond (1990), Fujita and Ramey (2009), Shimer (2012), and Elsby et al. (2015) for the algorithms of computing gross flows.
} 
show below that the relatively lower level of fluctuations in the participation rate should not be interpreted to suggest that movements into and out of the labor force are not quantitatively important. A key point is that changes in the labor force participation rate reflect net rather than gross flows; small changes in net flows are consistent with large changes in gross flows if the gross flows are partly offsetting.

Next we turn to the behavior of gross flows. We focus on the behavior of the transition rates between the three labor market states and, accordingly, define $f_{i j}$ to be the number of workers that move from state $i$ in the previous period to state $j$ in the current period, divided by the number of workers in state $i$ in the previous period. An important consideration when studying gross flows is the possibility of classification error. Whereas classification error might largely average out when computing labor market stocks, this is not the case with the gross flows between labor market states. Earlier work on this issue concludes that these errors are substantial, especially for flows between unemployment and non-participation. ${ }^{10}$

Following the approach in Krusell et al. (2017) we control for classification error using two different approaches. The first approach adjusts the gross flows data using Abowd and Zellner's (1985) estimates of misclassification probabilities. This method uses information from the CPS reinterview surveys. The second approach adjusts the gross flows using the "deNUNification" procedure introduced by Elsby et al. (2015). This reclassification procedure focuses on high frequency reversals of transitions between unemployment and non-participation. For example, if an individual's survey responses produce the sequence $N U N$, this is recoded as $N N N$. Importantly, the de $N U N$ ification procedure only addresses potential misclassification in the context of these flows.

\footnotetext{
${ }^{10}$ See, for example, Abowd and Zellner (1985), Poterba and Summers (1986), Chua and Fuller (1987), and Elsby et al. (2015).
} 
Table 2

\begin{tabular}{|c|c|c|c|c|c|c|c|c|c|c|c|}
\hline \multicolumn{12}{|c|}{ 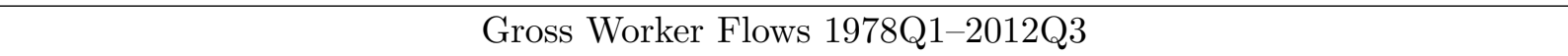 } \\
\hline \multicolumn{4}{|c|}{ Unadjusted Data } & \multicolumn{4}{|c|}{ Abowd-Zellner Correction } & \multicolumn{4}{|c|}{ DeNUNified Data } \\
\hline \multirow[t]{2}{*}{ FROM } & \multicolumn{3}{|c|}{ TO } & \multirow[t]{2}{*}{ FROM } & \multicolumn{3}{|c|}{ TO } & \multirow[t]{2}{*}{ FROM } & \multicolumn{3}{|c|}{ TO } \\
\hline & $E$ & $U$ & $N$ & & $E$ & $U$ & $N$ & & $E$ & $U$ & $N$ \\
\hline$E$ & 0.957 & 0.015 & 0.028 & $E$ & 0.972 & 0.014 & 0.014 & $E$ & 0.957 & 0.015 & 0.028 \\
\hline$U$ & 0.254 & 0.535 & 0.211 & $U$ & 0.228 & 0.637 & 0.135 & $U$ & 0.263 & 0.591 & 0.146 \\
\hline$N$ & 0.047 & 0.028 & 0.925 & $N$ & 0.022 & 0.021 & 0.957 & $N$ & 0.048 & 0.019 & 0.933 \\
\hline
\end{tabular}

Source: Krusell et al. (2017)

Table 2 presents the unadjusted average values of monthly transition rates for the 1978Q12012Q3 period, as well as the values based on each of the two adjustment procedures that we use. ${ }^{11}$ Comparing the first and second panels we see that applying the Abowd-Zellner correction increases the persistence for each state, i.e., the three diagonal terms. Although all entries are affected by the Abowd-Zellner adjustment, the largest absolute impact is on $f_{U U}$ and $f_{U N}$, which is consistent with the notion that the single most common misclassification is between $U$ and $N$. (The implied adjustments for $f_{N U}$ and $f_{N N}$ are much smaller in magnitude because the stock of workers in $N$ is much larger than the stock of workers in $U$.)

By design, the "deNUNification" procedure has no impact on the flows for individuals in the employment state, but all of the other flows are affected by the reclassification of workers between $U$ and $N$. Interestingly, both procedures have a similar impact on the values of $f_{U N}$ and $f_{N U}$.

In what follows we use the Abowd-Zellner corrected measures as our benchmark values for calibration. There are two reasons for this. First, the AZ adjustment is broader in scope, since it also directly affects transitions involving employment. For those components that are directly affected by both adjustments, the extent of the adjustment is similar. Second, the AZ adjustment is much less demanding to implement, and so will likely be used much more heavily. Nonetheless, in Appendix D we report results from an exercise in which we

\footnotetext{
${ }^{11}$ We do not make any correction for time aggregation. Because our model will allow for some time aggregation, the statistics in Table 2 are the relevant ones. In any case, time aggregation corrections do not alter any of the qualitative patterns that we comment on below. Shimer (2013) and Elsby et al. (2015) examine these flows using the time-aggregation corrected data and find the same cyclical properties as we do.
} 
use the statistics from the deNUNification adjustment to calibrate the model and find that the results are broadly similar. Because the two procedures differ and there is likely to be some noise when computing changes in gross flows over the business cycle, we will refer to both measures when evaluating the model's ability to account for cyclical fluctuations in the gross flows.

Next we turn to the cyclical behavior of the gross flows. Table 3 presents summary statistics for the business-cycle properties of the gross flows based on unadjusted data, AbowdZellner adjusted data, and deNUNified data. We produce quarterly data by computing the quarterly average of the monthly series, (i.e., we average the three monthly values for each $f_{i j}$ within a quarter), and then log and HP-filter each quarterly series with the smoothing parameter of 1600 .

Table 3

\begin{tabular}{|c|c|c|c|c|c|c|}
\hline \multicolumn{7}{|c|}{ Cyclical Properties of Gross Worker Flows 1978Q1-2012Q3 } \\
\hline \multicolumn{7}{|c|}{ Unadjusted Data } \\
\hline & $f_{E U}$ & $f_{E N}$ & $f_{U E}$ & $f_{U N}$ & $f_{N E}$ & $f_{N U}$ \\
\hline $\operatorname{std}(x)$ & 0.075 & 0.033 & 0.077 & 0.053 & 0.041 & 0.064 \\
\hline $\operatorname{corrcoef}(x, Y)$ & -0.70 & 0.35 & 0.79 & 0.66 & 0.61 & -0.70 \\
\hline $\operatorname{corrcoef}\left(x, x_{-1}\right)$ & 0.69 & 0.22 & 0.82 & 0.71 & 0.52 & 0.78 \\
\hline \multicolumn{7}{|c|}{ Abowd-Zellner (AZ) Correction } \\
\hline & $f_{E U}$ & $f_{E N}$ & $f_{U E}$ & $f_{U N}$ & $f_{N E}$ & $f_{N U}$ \\
\hline $\operatorname{std}(x)$ & 0.089 & 0.083 & 0.088 & 0.106 & 0.103 & 0.072 \\
\hline $\operatorname{corrcoef}(x, Y)$ & -0.63 & 0.43 & 0.76 & 0.61 & 0.52 & -0.23 \\
\hline $\operatorname{corrcoe} f\left(x, x_{-1}\right)$ & 0.59 & 0.29 & 0.75 & 0.62 & 0.38 & 0.30 \\
\hline \multicolumn{7}{|c|}{ DeNUNified Data } \\
\hline & $f_{E U}$ & $f_{E N}$ & $f_{U E}$ & $f_{U N}$ & $f_{N E}$ & $f_{N U}$ \\
\hline $\operatorname{std}(x)$ & 0.069 & 0.036 & 0.076 & 0.066 & 0.042 & 0.063 \\
\hline $\operatorname{corrcoef}(x, Y)$ & -0.66 & 0.29 & 0.81 & 0.55 & 0.57 & -0.56 \\
\hline $\operatorname{corrcoef}\left(x, x_{-1}\right)$ & 0.70 & 0.22 & 0.85 & 0.58 & 0.48 & 0.57 \\
\hline
\end{tabular}

Source: Krusell et al. (2017)

In Krusell et al. (2017) we noted some significant features from this table that we think are important to repeat here. First, the flows of individuals between participation and nonparticipation display large cyclical fluctuations. For example, looking at the AZ corrected flows, the volatility in the flows that involve out of the labor force are all similar in magnitude 
to the volatility of the flows between $E$ and $U$. That is, the gross flows data do not suggest that movements between participation and non-participation are of second order importance.

Second, some of the qualitative patterns in Table 3 do not seem intuitive. For example, we previously showed that the participation rate is modestly procyclical. This might lead one to intuitively expect that the two flows out of participation $\left(f_{E N}\right.$ and $\left.f_{U N}\right)$ would be countercyclical. But Table 3 indicates that both of these flows are procyclical. Related to this, it is often suggested as intuitive that $f_{U N}$ would be countercyclical, on the grounds that unemployed workers are more likely to become discouraged and leave the labor force during recessions. Importantly, the behavior of $f_{U N}$ is not inconsistent with the fact that the stock of discouraged workers is countercyclical: the higher stock of unemployed workers in recessions can lead to a higher stock of discouraged workers even with a lower transition rate.

\section{A Model of Gross Worker Flows in Steady State}

Motivated by the desire to connect with the previous facts, we build a model of worker flows in general equilibrium. We follow the now standard approach in the business cycle literature: first we develop a model that is consistent with steady state or average behavior, and then we subject it to shocks to study business cycle fluctuations. The objective of this section is to accomplish the first goal: to present a model whose steady state equilibrium can account for the salient facts about the average behavior of gross worker flows that we presented in the previous section.

Our model effectively merges a version of the Bewley-Huggett-Aiyagari heterogeneousagent incomplete markets model with a search model in the spirit of the Lucas-Prescott island economy. ${ }^{12}$ A large part of the model overlaps with Krusell et al. (2017), with the key distinction being that the current presentation is in general equilibrium whereas Krusell et

\footnotetext{
${ }^{12}$ Mortensen and Pissarides (1994) is an important contribution. See Rogerson et al. (2005) for an overview and additional references.
} 
al. (2017) treated prices and government transfers as exogenous. However, some elements are simplified compared to the Krusell et al. (2017) model, favoring transparency over realism.

The economy is populated by a unit mass of ex-ante identical individuals, each with preferences given by

$$
E_{t} \sum_{t=0}^{\infty} \beta^{t}\left[\log \left(c_{t}\right)-\alpha e_{t}-\gamma s_{t}\right]
$$

where $c_{t} \geq 0$ is consumption in period $t, e_{t} \in\{0,1\}$ is employment status in period $t$, and $s_{t} \in\{0,1\}$ is a discrete variable that reflects whether the individual engages in active job search in period $t$. We will refer to $s_{t}=1$ as reflecting active search and $s_{t}=0$ as reflecting passive search. The parameters $\alpha>0$ and $\gamma>0$ are the disutilities of work and active search, respectively, and $0<\beta<1$ is the discount factor.

A notable feature of the gross worker flows data is that the flow of individuals between $U$ and $N$ remains substantial even after attempting to clean the data of spurious moves. Intuitively, generating these flows requires shocks that lead to transitory fluctuations in an individual's desire to seek work. These shocks could potentially take a few different forms. We choose to introduce purely transitory shocks to $\gamma$, the disutility of active search. In particular, in our calibrated model we assume that draws are iid over time and distributed according to a five-point uniform distribution with mean $\bar{\gamma}$ and support $\left[\gamma_{\min }, \gamma_{\max }\right]$.

A second key source of exogenous idiosyncratic heterogeneity is that individuals face idiosyncratic shocks to their productivity in market work. We denote this idiosyncratic productivity by $z_{t}$ and assume it follows an $\operatorname{AR}(1)$ process in logs:

$$
\log z_{t+1}=\rho_{z} \log z_{t}+\varepsilon_{t+1},
$$

where the innovation $\varepsilon_{t}$ is a mean zero, normally distributed random variable with standard deviation $\sigma_{\varepsilon}$.

In reality, persistent differences in the desire to work might also reflect different valuations of non-market time, which in our framework would be captured by differences in $\alpha$, the 
disutility of market work. We abstract from this dimension of heterogeneity in order to economize on the dimension of the state space. From a conceptual perspective, what is key in our analysis is that cross-sectional heterogeneity in $z$ induces cross-sectional heterogeneity in the desire to work. This heterogeneity could be generated by heterogeneity in either the reward to market work or the costs of market work, and we do not think that the underlying source is important for our main results. ${ }^{13}$

To capture labor market frictions, we assume an island structure in the spirit of Lucas and Prescott (1974). We assume that there are two islands, one of which we label the production island, and the other of which we label as the leisure island. An individual can be on the production island or on the leisure island, whereas all firms operate on the production island. As in Krusell et al. (2017), this structure is sufficient for modeling flows into and out of employment.

To allow for job-to-job flows, we additionally assume that the production island consists of a continuum of districts. The significance of a district is that each individual has a timeinvariant idiosyncratic productivity component that is district specific. We will denote this component by $q_{i j}$ for individual $i$ in district $j$. If an individual with idiosyncratic productivity $z_{i t}$ works in district $j$, they provide $z_{i t} q_{i j}$ efficiency units of labor. For each individual the $q_{i j}$ are drawn from a lognormal distribution with mean 0 and standard deviation $\sigma_{q}$; when an individual receives an opportunity to work in a new district he or she will observe the realization of the $q_{i j}$ for that district. Realizations are iid across individuals and across districts.

Each district $j$ possesses a district level production function:

$$
Y_{j t}=Z K_{j t}^{\theta} L_{j t}^{1-\theta}
$$

where $K_{j t}$ is district-level input of capital services, $L_{j t}$ is district-level input of labor services

\footnotetext{
${ }^{13}$ Because the two sources of heterogeneity differ in terms of implications for productivity in market work, the source of heterogeneity can matter for the cyclical behavior of wages or productivity.
} 
in efficiency units, $Z$ is the aggregate TFP level (common to all districts and constant over time in the steady state model), and $0<\theta<1$. Output is homogeneous across districts and can be used either as consumption or investment, and capital depreciates at rate $\delta>0$.

Capital is freely mobile across districts, but movement of labor across islands and districts is subject to frictions. The labor market frictions are captured with four parameters$\lambda_{u}, \lambda_{n}, \lambda_{e}$, and $\phi$. The interpretation of these parameters is described below.

At the beginning of each period, a given individual finds themselves on one of the two islands, and if on the production island, in one of the districts. At this point the individual realizes new draws for their idiosyncratic productivity $z_{i t}$ and search cost $\gamma_{i t}$.

Consider first the situation faced by an individual who begins the period on the leisure island. This individual makes a discrete choice over search effort. An individual who chooses active search will move to the production island at the beginning of next period with probability $\lambda_{u}$, in a randomly assigned district. An individual who chooses to search passively will move to the production island at the beginning of next period with probability $\lambda_{n}$, again to a randomly assigned district. The subscripts $u$ and $n$ are chosen because the search intensity choice will determine how workers who begin a period on the leisure island are classified between unemployment and non-participation. If a worker who begins the period on the leisure island does not get relocated to the production island at the beginning of next period, they once again begin the following period on the leisure island.

Now consider an individual who begins the period in a particular district on the production island. We assume that one of three mutually exclusive events can occur. With probability $1-\phi-\lambda_{e}$, nothing new happens and the individual remains on the production island in the same district. With probability $\lambda_{e}$, the individual gets the opportunity to move to a different randomly drawn district $j^{\prime}$ and observes the value of $q_{i j^{\prime}}$. In equilibrium, the worker will move whenever $q_{i j^{\prime}}$ is larger than $q_{i j}$.

With probability $\phi$, the individual is separated from their district on the production 
island. But in the event that this happens, with probability $\lambda_{u}$ the individual immediately gets relocated to another randomly drawn district on the production island. ${ }^{14}$

And with probability $1-\lambda_{u}$ the individual is relocated to the leisure island and will then be in the same position as an individual who began the period on the leisure island. Once the randomness associated with these three potential events has been resolved, any individual who remains on the production island has the option to move to the leisure island. This voluntary movement to the leisure island typically occurs either when $z_{i t}$ becomes small or when the individual has accumulated a large amount of assets.

We are now in a position to describe more fully the sequence of events that unfold during a given time period. We assume that at the beginning of each period, each individual observes the new realization of their idiosyncratic shocks $z_{i t}$ and $\gamma_{i t}$ before making any decisions. After the realization of new $z_{i t}$ values, individuals who began on the production island (including those who newly arrived after being successful in search the previous period) see the realization of their frictional shocks and make labor supply (i.e., mobility) decisions. Individuals on the leisure island make search effort decisions. Then all individuals make consumption/savings decisions. The random outcomes of search for those on the leisure island are realized after the consumption/saving decision has been made.

Within a district we assume that the market for labor is competitive. Because of restrictions on labor mobility, this could lead to differences in the wage rate per efficiency unit of labor across districts. However, because we assume that capital is freely mobile across districts, it follows that the marginal product of capital will be equalized. With each district using the same constant returns to scale production function, this implies that the ratio of capital to efficiency units of labor will be the same across all districts, which in turn implies that the marginal product of an efficiency unit of labor will also be equalized. For this reason there will be a single wage rate per efficiency unit of labor.

\footnotetext{
${ }^{14}$ This captures the notion that employed individuals may have a network that makes it easier for them to locate alternative employment. It also allows for job to job moves that involve wage losses.
} 
In connecting with the data, we assume that individuals do not change jobs within a district, given that in equilibrium there is no gain from switching jobs within a district. ${ }^{15}$ Therefore, a job-to-job transition occurs only when the individual receives an opportunity to move to another district and the new draw of $q_{i j}$ is better than the current one.

For the capital market, we assume a market structure that is standard in much of the incomplete markets literature. There are no markets for insuring idiosyncratic risk, and the individual cannot borrow, but can self-insure by accumulating capital. We normalize the price of output to equal unity in each period and let $r$ and $w$ denote the rental rate of capital and the wage per efficiency unit of labor in steady state. To capture the presence of various transfer programs that implicitly provide some insurance, we assume that there is a proportional tax $\tau$ on labor earnings and a lump sum transfer $T$. Combining these features, the individual's period budget equation is given by:

$$
c_{t}+k_{t+1}=(1+r-\delta) k_{t}+(1-\tau) w z_{t} q_{t} e_{t}+T
$$

where, as above, $e_{t} \in\{0,1\}$ is the employment indicator. ${ }^{16}$

Textbook treatments of labor supply assume that prices (here, $w$ and $r$ ) are the key market conditions that an individual faces. Our analysis views the four frictional parameters as additional market conditions that individuals take as given. We collect all of the market conditions variables into a vector, $\Lambda \equiv\left(w, r, \lambda_{u}, \lambda_{n}, \lambda_{e}, \phi\right)$. Importantly, prices will be endogenously determined in equilibrium, but the four frictional parameters will be taken as exogenous.

We represent equilibrium for this economy recursively. We define value functions at the point where all new shocks have been realized, so that the individual knows the current value

\footnotetext{
${ }^{15}$ If we assumed an infinitesimal cost of changing jobs then workers would strictly prefer not to change jobs within a district, and the impact on moving across districts would not be affected to first order.

${ }^{16}$ One difference from the specification in Krusell et al. (2017) is that here we abstract from the UI system. This is done largely to facilitate exposition as this increases the size of the state space and introduces quite a bit of additional notation. The presence of an empirically reasonable UI system does affect some of the model properties.
} 
of $z$, the current value of $\gamma$, whether they have an employment opportunity and if so the value of the match quality, and the capital brought into the period. Because we focus on a steady state equilibrium in this section, for now we suppress the dependence of value functions on the variables that describe market conditions, as these will be constant in steady state.

Define $U(k, z, \gamma)$ to be the optimal value for an individual who is on the leisure island and chooses to search actively this period, and $N(k, z, \gamma)$ to be the optimal value for an individual who is on the leisure island and chooses to search passively this period. The optimal value for an individual on the leisure island, prior to deciding on search activity, which we denote by $J(k, z, \gamma)$, will just be the maximum of these two values:

$$
J(k, z, \gamma)=\max \{U(k, z, \gamma), N(k, z, \gamma)\}
$$

Denote the value from working on the production island for an individual with assets $k$, idiosyncratic productivity $z$, and idiosyncratic district-specific match quality $q$ by $W(k, z, q)$. Note that the value of $\gamma$ does not appear as an argument of this value function since search costs are irrelevant for employed individuals.

Denote the optimal value for an individual who is on the production island, with individual state vector $(k, z, q, \gamma)$ as $V(k, z, q, \gamma)$. This value reflects the optimal choice between working and not working, i.e., returning to the leisure island:

$$
V(k, z, q, \gamma)=\max \{W(k, z, q), J(k, z, \gamma)\}
$$

With this notation presented we can now write down each of the individual Bellman equations. For the value of active search we have:

$$
U(k, z, \gamma)=\max _{c \geq 0, k^{\prime} \geq 0}\left\{\ln c-\gamma+\beta E_{z^{\prime}, q^{\prime}, \gamma^{\prime}}\left[\lambda_{u} V\left(k^{\prime}, z^{\prime}, q^{\prime}, \gamma^{\prime}\right)+\left(1-\lambda_{u}\right) J\left(k^{\prime}, z^{\prime}, \gamma^{\prime}\right)\right]\right\}
$$

subject to

$$
c+k^{\prime}=(1+r-\delta) k+T \text {. }
$$


For the value of passive search we have:

$$
N(k, z, \gamma)=\max _{c \geq 0, k^{\prime} \geq 0}\left\{\ln c+\beta E_{z^{\prime}, q^{\prime}, \gamma^{\prime}}\left[\lambda_{n} V\left(k^{\prime}, z^{\prime}, q^{\prime}, \gamma^{\prime}\right)+\left(1-\lambda_{n}\right) J\left(k^{\prime}, z^{\prime}, \gamma^{\prime}\right)\right]\right\}
$$

subject to

$$
c+k^{\prime}=(1+r-\delta) k+T \text {. }
$$

Both of these Bellman equations are very easy to follow as the right hand sides reflect the two possible outcomes for next period depending upon whether search is successful or not.

The Bellman equation for $W(k, z, q)$ is a bit more complicated and reads:

$$
\begin{array}{r}
W(k, z, q) \\
=\max _{c \geq 0, k^{\prime} \geq 0}\left\{\ln c-\alpha+\beta E_{z^{\prime}, q^{\prime}, \gamma^{\prime}}\left[\left(1-\phi-\lambda_{e}\right) V\left(k^{\prime}, z^{\prime}, q, \gamma^{\prime}\right)+\lambda_{e}\left\{V\left(k^{\prime}, z^{\prime}, \max \left\{q, q^{\prime}\right\}, \gamma^{\prime}\right)\right.\right.\right. \\
\left.+\phi\left\{\left(1-\lambda_{u}\right) J\left(k^{\prime}, z^{\prime}, \gamma^{\prime}\right)+\lambda_{u} V\left(k^{\prime}, z^{\prime}, q^{\prime}, \gamma^{\prime}\right\}\right]\right\}
\end{array}
$$

subject to

$$
c+k^{\prime}=(1+r-\delta) k+(1-\tau) w z q+T .
$$

Note that the right hand side of the Bellman equation reflects the three different events that may happen to this worker. If the worker is not displaced and does not receive a new opportunity in a different district, then next period they will decide between working in the same district and leaving for the leisure island. If the individual is not displaced and receives a draw from another district, then they will move to the new district if and only if the new district offers a higher value of $q$, and at that point will face the decision of working versus moving to the leisure island. The final possibility is that the individual receives a separation shock. With probability $\lambda_{u}$ they immediately move to another randomly drawn district, but with probability $1-\lambda_{u}$ they move to the leisure island.

Let $\mu\left(I_{e}, k, z, q, \gamma\right)$ denote the measure of individuals across idiosyncratic states at the beginning of the period, where $I_{e}$ is an indicator function equalling 1 if the individual begins on the production island and 0 otherwise. A steady state equilibrium is a list of value functions $(U, N, V, J, W)$, decision rules $c, k^{\prime}, s, e$, a measure $\mu^{*}$, aggregates $\left(K^{*}, L^{*}, T^{*}\right)$ and prices $\left(r^{*}, w^{*}\right)$ such that: 
(1) The value functions satisfy (1), (2), (3), (4), and (5) and the decision rules are the corresponding optimal decisions.

(2) Given $\mu^{*}$, optimal household decisions imply aggregate outcomes for supply of capital and labor of $K^{*}$ and $L^{*}$.

(3) $K^{*}$ and $L^{*}$ are solutions to:

$$
\max _{K, L} Z K^{\theta} L^{1-\theta}-r^{*} K-w^{*} L
$$

(4) The government budget constraint is satisfied:

$$
T^{*}=\tau w^{*} \int_{e_{i}=1} z_{i} q_{i} d i
$$

(5) Optimal decisions by workers starting from the distribution $\mu^{*}$ results in the same distribution over individual states next period.

We note that condition (3) implies that prices will satisfy:

$$
r^{*}=Z\left(\frac{K^{*}}{L^{*}}\right)^{\theta-1}
$$

and

$$
w^{*}=Z\left(\frac{K^{*}}{L^{*}}\right)^{\theta}
$$

The government budget equation implies that all government revenues are rebated back to households as a lump sum transfer. Because we have a one good model, there is no distinction between the government transferring purchasing power to households and the government providing consumption directly to households. But some government spending, such as national defense, might best be viewed as spending that does not yield utility to households. ${ }^{17}$ In Appendix $\mathrm{C}$ we consider a specification in which a fixed amount of government revenue is spent on activities that do not contribute to individual utility and find that it has virtually no effect on our findings.

\footnotetext{
${ }^{17} \mathrm{Or}$, equivalently for our purposes, it could be viewed as providing utility that is separable from the utility from private consumption.
} 


\section{Steady State Calibration}

This section describes our procedure for calibrating the parameters of our model to match steady state observations. Because data on labor-market transitions are available monthly, we set the length of a period to be one month. Although we solve the model at monthly frequency, when we study business cycles we will generate data at quarterly frequency by computing three month averages for the relevant statistics.

Several parameters are set without solving the model. We set $Z=1$ as this reflects a choice of units. We set $\theta$, the capital share in the production function, equal to 0.30 . We calibrate the idiosyncratic shock process $z$ to estimates of idiosyncratic wage shocks, and so assume an $\mathrm{AR}(1)$ process, with the monthly persistence parameter $\rho_{z}=0.996$ and the standard deviation of shocks $\sigma_{z}=0.096$. Aggregated to an annual level, this would correspond to persistence of 0.955 and a standard deviation of 0.20 , which we take as representative values from this literature. ${ }^{18}$ In line with various studies, we set $\tau=0.30 .{ }^{19}$ The lump-sum transfer $T$ will be determined by the requirement that the government budget balances in steady-state equilibrium.

The remaining parameters are chosen so that the steady-state equilibrium matches specific targets. Although this amounts to a large set of nonlinear equations which is solved jointly, we think it is informative to describe the calibration as a few distinct steps. Because this part of the calibration mirrors that in Krusell et al. (2017) we refer the reader there for additional discussion.

We begin with the five parameters $\alpha, \bar{\gamma}, \phi, \lambda_{u}$, and $\lambda_{n}$. We fix the value of $\bar{\gamma}$ relative to the value of $\alpha$ based on measures of search versus work time. Using data from the American Time Use Survey (ATUS), Mukoyama et al. (2018) report that unemployed workers devote

\footnotetext{
${ }^{18}$ See for example, estimates in Card (1994), Floden and Linde (2001), and French (2005). We convert the annual value into the monthly value using the approximation method of Chang and Kim (2006).

${ }^{19}$ Following the work of Mendoza et al. (1994) there are several papers which produce estimates of the average effective tax rate on labor income across countries. Minor variations in methods across these studies produce small differences in the estimates, but 0.30 is representative of these estimates.
} 
approximately 3.5 hours per week to search on average, whereas employed individuals work approximately 40 hours. Based on this we set $\bar{\gamma}=\frac{3.5}{40} \alpha$. The values of $\alpha, \phi, \lambda_{u}$, and $\lambda_{n}$ are set to match the labor force participation rate $(0.66)$, the unemployment rate $(0.068)$, the $E$-to- $U$ flow rate $(0.014)$, and the $N$-to- $E$ flow rate $(0.022) .{ }^{20}$

The values of $\lambda_{e}$ and $\sigma_{q}$ are set to match two statistics related to job-to-job transitions. The first is a job-to-job transition rate of $2.2 \%$ per month (from the CPS, using the tabulation of Fallick and Fleischman (2004) for 1994Q1 to 2012Q3), and the second is the average wage gain of 3.3\% (from Tjaden and Wellschmied (2014)) for an individual that experiences a job-to-job transition.

The final preference parameter to be determined is the dispersion of the shock to $\gamma$ : $\zeta_{\gamma} \equiv \bar{\gamma}-\gamma_{\min }=\gamma_{\max }-\bar{\gamma}$, which governs the variation in the disutility associated with active search. As noted earlier, we set $\zeta_{\gamma}$ so as to match the flow from $U$ to $N$.

We set the depreciation rate to correspond to an annual rate of 0.067 . $\beta$ is set so that $1+r-\delta$ is equal to 1.00327 (1.04 when measured annually). This leads us to $\beta=0.9946$. In the steady state equilibrium we have $w=2.48$ and $T=1.36$.

Table 4

\begin{tabular}{cccccccccccc}
\hline \hline \multicolumn{110}{c}{ Calibrated Parameter Values } \\
\hline$\beta$ & $\rho_{z}$ & $\sigma_{z}$ & $\alpha$ & $\lambda_{u}$ & $\lambda_{n}$ & $\lambda_{e}$ & $\phi$ & $\sigma_{q}$ & $\bar{\gamma}$ & $\gamma_{\min }$ & $\gamma_{\max }$ \\
0.9946 & 0.996 & 0.096 & 0.478 & 0.276 & 0.157 & 0.079 & 0.0235 & 0.0375 & 0.042 & 0.015 & 0.068 \\
\hline \hline
\end{tabular}

Table 5 shows the implications of our calibrated model for steady state gross worker flows. For completeness we include the corresponding values from the AZ-Adjusted data with bootstrapped confidence intervals. The computational method for the steady state model is detailed in Appendix A.

\footnotetext{
${ }^{20}$ All these values are averages from 1978 Q1 to $2012 \mathrm{Q} 3$.
} 
Table 5

\begin{tabular}{|c|c|c|c|c|c|c|c|}
\hline \multicolumn{8}{|c|}{ Gross Worker Flows in the Data and the Model } \\
\hline \multicolumn{4}{|c|}{ AZ-Adjusted Data } & \multicolumn{4}{|c|}{ Model } \\
\hline \multirow[t]{2}{*}{ FROM } & \multicolumn{3}{|c|}{ TO } & \multirow[t]{2}{*}{ FROM } & \multicolumn{3}{|c|}{ TO } \\
\hline & $E$ & $U$ & $N$ & & $E$ & $U$ & $N$ \\
\hline$E$ & 0.972 & 0.014 & 0.014 & $E$ & 0.968 & 0.014 & 0.018 \\
\hline $95 \% \mathrm{CI}$ & $(0.970,0.974)$ & $(0.013,0.015)$ & $(0.012,0.015)$ & & & & \\
\hline$U$ & 0.228 & 0.637 & 0.135 & $U$ & 0.270 & 0.618 & 0.111 \\
\hline $95 \% \mathrm{CI}$ & $(0.211,0.246)$ & $(0.616,0.657)$ & $(0.119,0.152)$ & & & & \\
\hline$N$ & 0.022 & 0.021 & 0.957 & $N$ & 0.022 & 0.025 & 0.953 \\
\hline $95 \% \mathrm{CI}$ & $(0.019,0.025)$ & $(0.018,0.023)$ & $(0.954,0.960)$ & & & & \\
\hline
\end{tabular}

While our calibration does not yield gross flows that lie within each of the $95 \%$ confidence intervals, the match is quite close overall and does not yield any large gaps between the model and the data. ${ }^{21}$ It is of particular note that we are able to do a very good job of replicating the flows between $U$ and $N$, as this has proven very difficult for past efforts. (See, for example, Garibaldi and Wasmer (2005) and Krusell et al. (2011).)

\section{Business Cycle Analysis}

Having developed and calibrated a model that can replicate the salient facts about steady state or average outcomes, in this section we expose our calibrated economy to aggregate shocks and examine the properties of business cycles. We proceed in two steps. In the first subsection, we carry out a "traditional" RBC exercise and consider aggregate TFP shocks to be the sole source of shocks to the economy. In the following subsection, we consider shocks to the frictional parameters: $\lambda_{u}, \lambda_{n}, \lambda_{e}$, and $\phi$.

The computation of the model follows the methodology of Boppart et al. (2018). Details on computation of the business cycle model are included in Appendix B.

\footnotetext{
${ }^{21}$ We note that in Krusell et al. (2017) our specification generated values that were all within the 95\% confidence intervals. This reflects the fact that a UI system does have some impact on the model's implications for flows. In particular, the UI system helps to increase the persistence of the $U$ state. Nonetheless, given the close match of the current calibration it seems reasonable to view these impacts as second order.
} 


\subsection{TFP Shocks}

In this subsection we subject our economy to aggregate TFP $(Z)$ shocks. Absent labor market frictions, our model closely resembles the incomplete-market/heterogeneous-agent model of Chang and Kim (2006) that extended the indivisible-labor model of Hansen (1985) and Rogerson (1988). Those models were viewed as successfully generating an important share of aggregate fluctuations in employment via intertemporal substitution effects in the presence of aggregate TFP shocks.

Importantly, those earlier RBC analyses focused only on movements in aggregate employment. That is, they abstracted from the division of non-employment into unemployment and non-participation, and did not study the behavior of gross worker flows. Our model allows us to study these additional implications.

As is described in Appendix B, the computational method of Boppart et al. (2018) involves choosing the baseline deviation (denoted $\epsilon_{Z}$ for the TFP shock) in the deterministic simulation and the scale parameter (denoted by $\omega_{Z}$ ) in the stochastic simulation. The combination of these two determines the size (dispersion) of the shock. We choose $\epsilon_{Z}=0.01$. The value of $\omega_{Z}$ is chosen so that the resulting model generates the same fluctuations in employment as found in the data when the cyclical component is defined using an HP filter. This procedure yields $\omega_{Z}=2.53$, which means that the size of the shocks $\left(\sigma_{Z}\right.$ in the notation of Appendix B) corresponds to a standard deviation of 0.0253 in the context of an $\mathrm{AR}(1)$ specification. The persistence parameter (denoted as $\rho$ in Appendix B) is set at 0.983 , as in Krusell et al. (2017).

Because we calibrate the size of the aggregate shocks so as to perfectly match the volatility of employment fluctuations, we are obviously not addressing the issue of whether our model can generate the size of employment fluctuations in the data, a question that the earlier papers

in the literature tended to focus on. Rather, the question we ask here is whether, conditional on being able to explain the size of fluctuations in employment, this framework would pass 
the higher threshold of accounting for the behavior of unemployment, participation, and the gross flows.

Table 6

\begin{tabular}{c|ccc|ccc}
\hline \hline \multicolumn{6}{c}{ Cyclical Behavior of Stocks With Only TFP Shocks } \\
\hline & \multicolumn{3}{|c|}{ Data } & \multicolumn{3}{c}{ Model } \\
\hline & $u$ & $l f p r$ & $E$ & $u$ & $l f p r$ & $E$ \\
$\operatorname{std}(x)$ & 0.117 & 0.0026 & 0.0099 & 0.030 & 0.0157 & 0.0099 \\
$\operatorname{corrcoef}(x, Y)$ & -0.84 & 0.21 & 0.83 & 0.11 & 0.96 & 0.94 \\
$\operatorname{corrcoef}\left(x, x_{-1}\right)$ & 0.93 & 0.69 & 0.92 & 0.52 & 0.85 & 0.87 \\
\hline \hline
\end{tabular}

Tables 6 and 7 show the key results, with Table 6 reporting the cyclical behavior of the stocks and Table 7 reporting the cyclical behavior of the gross flows. We begin by examining the results in Table 6. As just noted, by design the model accounts for the magnitude of fluctuations in employment. As the table indicates, it also closely matches the persistence and cyclicality of employment fluctuations, though neither of these is at all surprising in this context. Although the model therefore does a good job of accounting for the key features of cyclical fluctuations in employment, it has decidedly counterfactual predictions with regard to both unemployment and participation.

Consider first the properties of the participation rate. In the data, the participation rate fluctuates about one fourth as much as the employment rate. In the model with only TFP shocks, the participation rate fluctuates more than 1.5 times as much as employment. And whereas in the data the participation rate is only mildly procyclical, in the model it is as procyclical as employment.

The behavior of unemployment is also strongly counterfactual. In the data the unemployment rate fluctuates more than employment, but in the model it fluctuates only $30 \%$ as much. And whereas the unemployment rate is strongly countercyclical in the data, in the model with only TFP shocks it is mildly procyclical. The unemployment rate also exhibits much less persistence in the model than in the data.

In terms of broad characterizations, the following patterns emerge. In the data, employment fluctuations are to first approximation balanced out by offsetting fluctuations in 
unemployment with relatively small adjustments in participation. But in the model with only TFP shocks, employment fluctuations are basically matched by fluctuations in participation, with minor adjustments in unemployment.

What is the intuition for the qualitative features of fluctuations in this model? The basic economics behind these patterns is effectively the economics of employment fluctuations in standard RBC models without frictions. Fluctuations in aggregate TFP lead to fluctuations in wages, and individuals respond by trying to work more when wages are high. When aggregate TFP increases, this causes more non-employed individuals to search actively since this increases their chances of having the opportunity to work. This leads to an immediate increase in participation and unemployment. Although the shock is persistent, the increase in unemployment is not persistent because active searchers make their way into employment, thus leaving unemployment.

This basic mechanism means that participation and employment move closely together and that relatively transient procyclical movements in unemployment are just a by-product of workers choosing to coordinate periods of work with periods of high wages. Loosely speaking, one might view the indivisible labor models of Hansen (1985) and Chang and Kim (2006) as models of participation, since in those models any individual who desires to be employed will be employed. 
Table 7

\begin{tabular}{|c|c|c|c|c|c|c|}
\hline \multicolumn{7}{|c|}{ Cyclical Behavior of Gross Worker Flows With Only TFP Shocks } \\
\hline \multicolumn{7}{|c|}{ A. AZ-Adjusted Data } \\
\hline & $f_{E U}$ & $f_{E N}$ & $f_{U E}$ & $f_{U N}$ & $f_{N E}$ & $f_{N U}$ \\
\hline $\operatorname{std}(x)$ & 0.089 & 0.083 & 0.088 & 0.106 & 0.103 & 0.072 \\
\hline $\operatorname{corrcoef}(x, Y)$ & -0.63 & 0.43 & 0.76 & 0.61 & 0.52 & -0.23 \\
\hline $\operatorname{corrcoef}\left(x, x_{-1}\right)$ & 0.59 & 0.29 & 0.75 & 0.62 & 0.38 & 0.30 \\
\hline \multicolumn{7}{|c|}{ B. DeNUNified Data } \\
\hline & $f_{E U}$ & $f_{E N}$ & $f_{U E}$ & $f_{U N}$ & $f_{N E}$ & $f_{N U}$ \\
\hline $\operatorname{std}(x)$ & 0.069 & 0.036 & 0.076 & 0.066 & 0.042 & 0.063 \\
\hline $\operatorname{corrcoef}(x, Y)$ & -0.66 & 0.29 & 0.81 & 0.55 & 0.57 & -0.56 \\
\hline $\operatorname{corrcoe} f\left(x, x_{-1}\right)$ & 0.70 & 0.22 & 0.85 & 0.58 & 0.48 & 0.57 \\
\hline \multicolumn{7}{|c|}{ C. Model } \\
\hline & $f_{E U}$ & $f_{E N}$ & $f_{U E}$ & $f_{U N}$ & $f_{N E}$ & $f_{N U}$ \\
\hline $\operatorname{std}(x)$ & 0.014 & 0.108 & 0.004 & 0.070 & 0.059 & 0.083 \\
\hline $\operatorname{corr}(x, Y)$ & 0.88 & -0.46 & 0.49 & -0.69 & 0.43 & 0.05 \\
\hline $\operatorname{corr}\left(x, x_{-1}\right)$ & 0.68 & 0.24 & 0.68 & 0.66 & 0.51 & 0.34 \\
\hline
\end{tabular}

We now turn to the results for the cyclical behavior of gross flows, presented in Table 7. Given that the model fails quite substantially to replicate the key features of the stocks it must necessarily fail to match some of the patterns in the gross flow data, and Table 7 clearly illustrates this. In particular, four of the six flows have the wrong cyclicality, and in the model, each of the flows between employment and unemployment move very little relative to the data. The somewhat surprising and counterfactual procyclical movement in $f_{E U}$ in the model is driven by the behavior of employed individuals who experience a separation shock and are displaced from the production island. During good times, these individuals are more likely to want to return to the production island to take advantage of the higher wages, making it more likely that they will choose to search actively.

The key message that we take away from this exercise is the following. Although traditional RBC models are capable of generating empirically reasonable fluctuations in employment in the presence of aggregate TFP shocks, when one extends these models to include labor market frictions (so as to distinguish between unemployment and non-participation), they are not able to capture the richer set of patterns found in the data holding frictional parameters fixed. That is, labor supply responses due purely to TFP-induced price changes 
cannot account for a richer set of facts about labor market fluctuations. In the next subsection we consider shocks to the frictional parameters as well and show that in this case we are able to capture many of the salient features of the data.

\subsection{Shocks to Frictions}

In the previous section, we considered the case in which a shock to aggregate TFP was the only shock. Here we generalize this by assuming that each aggregate state corresponds to a realization for aggregate TFP and the four frictional parameters. That is, $Z, \lambda_{u}, \lambda_{n}, \lambda_{e}$, and $\phi$ move together.

As in the case with only TFP shocks, the method of Boppart et al. (2018) requires us to set the baseline $\log$-deviations $\epsilon_{Z}, \epsilon_{\lambda}$, and $\epsilon_{\phi}$, as well as the scale parameters for shocks $\omega_{Z}$, $\omega_{\lambda}$, and $\omega_{\phi}$. The resulting standard deviation of the shock, denoted by $\sigma_{k}$, is determined by $\sigma_{k}=\omega_{k} \epsilon_{k}$ for $k=Z, \lambda$, and $\phi$. We first set $\epsilon_{Z}=0.01, \epsilon_{\lambda}=0.2$, and $\epsilon_{\phi}=0.1$. As in the previous experiment, we assume the persistence parameter $\rho=0.983$. Note that $Z, \lambda_{u}, \lambda_{n}$, and $\lambda_{e}$ are perfectly positively correlated with each other, whereas $\phi$ is perfectly negatively correlated with the other four. Below, we call the situations with high $Z$ "good times" and the situations with low $Z$ "bad times". Expansions occur when a positive shock to $Z$ arrives, and recessions occur when a negative shock to $Z$ arrives.

The values of the scale parameters $\omega_{Z}, \omega_{\lambda}$, and $\omega_{\phi}$ are set so that the model statistics match the following targets. In our model, both the level and fluctuations in $f_{U E}$ closely mimic the level and fluctuations in $\lambda_{u}$. For this reason we choose the value of $\omega_{\lambda}$ so that the fluctuations in $f_{U E}$ in the simulated model match the standard deviation of the fluctuations in $f_{U E}$ found in US data. This leads to $\omega_{\lambda}=0.21$, implying $\sigma_{\lambda}=0.042$. Given values for the $\lambda_{i}$ 's, which influence the impact of time aggregation on measured $f_{E U}$, the level and fluctuations in $f_{E U}$ closely follow the level and fluctuations in $\phi$, so we choose $\omega_{\phi}=0.30$ so as to match the fluctuations in $f_{E U}$. This value of $\omega_{\phi}$ implies $\sigma_{\phi}=0.030$. We match the above volatility values based on the Abowd-Zellner correction procedure. Similar to what 
we did in the previous subsection, we set $\omega_{Z}$ so as to generate fluctuations in $E$ that match those in the data. This leads to $\omega_{Z}=0.67$, implying $\sigma_{Z}=0.0067$. Table 8 summarizes the calibration of the magnitudes of the shocks that we consider.

Table 8

\begin{tabular}{ccc}
\hline \hline \multicolumn{3}{c}{ Calibration of Shocks } \\
\hline$\sigma_{Z}$ & $\sigma_{\lambda}$ & $\sigma_{\phi}$ \\
0.0067 & 0.042 & 0.030 \\
\hline \hline
\end{tabular}

Table 9

\begin{tabular}{c|ccc|ccc}
\hline \hline \multicolumn{6}{c}{ Cyclical Behavior of Stocks With TFP and Friction Shocks } \\
\hline & \multicolumn{3}{|c|}{ Data } & \multicolumn{3}{c}{ Model } \\
\hline & $u$ & $l f p r$ & $E$ & $u$ & lfpr & $E$ \\
$\operatorname{std}(x)$ & 0.117 & 0.0026 & 0.0099 & 0.138 & 0.0024 & 0.0099 \\
$\operatorname{corrcoef}(x, Y)$ & -0.84 & 0.21 & 0.83 & -0.89 & 0.78 & 0.96 \\
$\operatorname{corrcoef}\left(x, x_{-1}\right)$ & 0.93 & 0.69 & 0.92 & 0.89 & 0.80 & 0.89 \\
\hline \hline
\end{tabular}

The key results for cyclical fluctuations are presented in Tables 9 and 10, with Table 9 presenting properties of the fluctuations in labor market stocks, and Table 10 reporting properties of fluctuations in gross worker flows. We begin with the results in Table 9. In sharp contrast to the results in Table 6 when TFP shocks were the only shocks, we see that the model with a richer set of shocks is much more successful in capturing the key qualitative and quantitative patterns in the data. As in the previous subsection, the calibration effectively ensures that employment fluctuations in the model will closely resemble those in the data. But importantly, the model is now able to capture the fact that employment fluctuations are largely offset by fluctuations in unemployment, with small and somewhat less procyclical movements in the participation rate. To a first order, the model captures not only the relative magnitudes of fluctuations of the three stocks, but also the cyclicality and persistence properties.

While the model is largely successful, we do want to highlight two outcomes. First, the model delivers a correlation between employment and output that is too high relative to the data. We believe that this is largely an artifact of our assumed shock structure. In particular, we assume that all of the shocks move together, and we do not have any purely temporary 
shocks that might move output independently of employment. Second, although the model implies that the participation rate is less correlated with output than is employment, it does not generate as large a gap between them as is found in the data. As we show in more detail in the next section, TFP shocks generate a high positive correlation between participation and output, so this gap is sensitive to the relative importance of TFP shocks. In this exercise we have imposed that TFP shocks account for all employment fluctuations not accounted for by our measured changes in frictions. An important area for future work is to consider how additional shocks and propagation mechanisms might affect the properties of fluctuations.

Although the model does a reasonably good job of empirically accounting for the cyclical fluctuations of the three labor market stocks, it does not follow that it will necessarily do a good job of accounting for the cyclical properties of the gross flows. To examine this we now turn to the results in Table 10.

Table 10

\begin{tabular}{|c|c|c|c|c|c|c|}
\hline \multicolumn{7}{|c|}{ Cyclical Behavior of Gross Worker Flows With TFP and Friction Shocks } \\
\hline \multicolumn{7}{|c|}{ A. AZ-Adjusted Data } \\
\hline & $f_{E U}$ & $f_{E N}$ & $f_{U E}$ & $f_{U N}$ & $f_{N E}$ & $f_{N U}$ \\
\hline $\operatorname{std}(x)$ & 0.089 & 0.083 & 0.088 & 0.106 & 0.103 & 0.072 \\
\hline $\operatorname{corrcoef}(x, Y)$ & -0.63 & 0.43 & 0.76 & 0.61 & 0.52 & -0.23 \\
\hline $\operatorname{corrcoef}\left(x, x_{-1}\right)$ & 0.59 & 0.29 & 0.75 & 0.62 & 0.38 & 0.30 \\
\hline \multicolumn{7}{|c|}{ B. DeNUNified Data } \\
\hline & $f_{E U}$ & $f_{E N}$ & $f_{U E}$ & $f_{U N}$ & $f_{N E}$ & $f_{N U}$ \\
\hline $\operatorname{std}(x)$ & 0.069 & 0.036 & 0.076 & 0.066 & 0.042 & 0.063 \\
\hline $\operatorname{corrcoef}(x, Y)$ & -0.66 & 0.29 & 0.81 & 0.55 & 0.57 & -0.56 \\
\hline $\operatorname{corrcoe} f\left(x, x_{-1}\right)$ & 0.70 & 0.22 & 0.85 & 0.58 & 0.48 & 0.57 \\
\hline \multicolumn{7}{|c|}{ C. Model } \\
\hline & $f_{E U}$ & $f_{E N}$ & $f_{U E}$ & $f_{U N}$ & $f_{N E}$ & $f_{N U}$ \\
\hline $\operatorname{std}(x)$ & 0.089 & 0.038 & 0.088 & 0.031 & 0.056 & 0.095 \\
\hline $\operatorname{corr}(x, Y)$ & -0.97 & 0.20 & 0.96 & 0.37 & 0.76 & -0.95 \\
\hline $\operatorname{corr}\left(x, x_{-1}\right)$ & 0.81 & -0.15 & 0.80 & 0.59 & 0.66 & 0.87 \\
\hline
\end{tabular}

Overall, the results in Table 10 support the view that the model is not only able to capture the qualitative properties of fluctuations in gross worker flows, but is also broadly successful quantitatively. In particular, the model is able to capture the cyclicality of all six flows, including those that might seem counterintuitive.

To be clear, there are some discrepancies between the data and the model in terms of the 
magnitudes of fluctuations for some of the flows, but on this point we think it is important to note that the alternative method for correcting for classification error (what we refer to as "deNUNification") implies levels of volatility that are in some cases more in line with those predicted by our model. In view of this, we feel that less weight should be attached to the discrepancies in volatility levels in Table 10.

Some of the properties revealed in Table 10 are easily understood. For example, the procyclicality of $f_{U E}$ is driven by the procyclical shocks to $\lambda_{u}$, and the countercyclicality of $f_{E U}$ is mechanically driven by the countercyclical shocks to $\phi$. What is more interesting is that the model is able to replicate two flows that at first pass appear to be somewhat counterintuitive. Specifically, $f_{E N}$ and $f_{U N}$ are both procyclical despite the fact that the stock of workers in $N$ is countercyclical. In what follows we therefore focus on describing the economics behind these patterns. Our discussion will focus on how these patterns are shaped by shocks to the frictional parameters, since the model without TFP shocks is not able to capture the cyclicality of these flows.

As noted in Krusell et al. (2017), the key to understanding the procyclical flow from $U$ to $N$ lies in understanding the role that time-varying frictions play in shaping the composition of the unemployment pool. At any point in time, non-employed individuals vary with regard to their individual state vectors, as denoted by $(k, z, \gamma)$. Variation in these values leads some to search actively and some to search passively. This two-way classification creates a boundary in the space of individual characteristics for these individuals. Importantly, some of these individuals will be close to the boundary and others will be far away from the boundary. An individual who chooses to search actively and is far away from the boundary is much less likely to transition to $N$ than is an individual who chooses to search actively and is close to the boundary. It follows that the rate at which individuals transition from $U$ to $N$ will depend on the distribution of distance from the boundary.

With this in mind, we describe two factors that make it more likely that active searchers 
are close to the boundary in good times. Note that there are two ways that an individual transitions into the $U$ state: either from $E$ or from $N$. Individuals who enter from $N$ are inherently more likely to be close to the $U-N$ boundary given that they are coming from $N$. In good times, $\phi$ is lower, implying fewer separations out of employment, and as a result, a smaller flow of individuals into $U$ from $E$. At the same time, because $\lambda_{u}$ is higher, active searchers are more likely to leave $U$ for $E$. This implies that a greater fraction of the individuals in $U$ are individuals that have just recently entered into $U$. Workers who have transitioned from $N$ into $U$ are more likely to be very close to the boundary right after having crossed the boundary.

For these two reasons, the composition of the unemployed pool in good times is more likely to disproportionately contain individuals who are close to the $U-N$ boundary, and therefore exhibit a higher propensity for movements back into $N$. These composition effects are consistent with the empirical findings of Elsby et al. (2015), who show that in the CPS data, the composition of the unemployed pool shifts towards more "attached" workers during recessions, where the most important dimension of attachment is prior employment status. They show that this mechanism accounts for around 75 percent of the decline in the $U N$ flow rate during recessions. The importance of composition effects in generating the procyclical movement in $f_{U N}$ underscores the importance of modeling heterogeneity in order to account for the empirical patterns in gross worker flows. ${ }^{22}$

The procyclicality of $f_{E N}$ reflects the option value of employment in a frictional labor market. When it is relatively difficult to find employment, an employed individual may be reluctant to move out of employment even if it is optimal not to work from a static perspective. This is because the individual realizes that if they leave employment this period, they cannot immediately re-enter employment in the future if their circumstances change. In

\footnotetext{
${ }^{22}$ Appendix D examines the case where we target the $f_{E U}$ and $f_{U E}$ fluctuations in the de $N U N$ ified data in determining the magnitude of $\lambda$ and $\phi$ shocks. The magnitude of these shocks are considerably smaller in that calibration, because $f_{E U}$ and $f_{U E}$ fluctuations are smaller in deNUNified data. Consistent with the above argument, $f_{U N}$ becomes countercyclical in that case, because the composition effect is significantly weaker.
} 
the limit as frictions disappear, this option value would disappear. Because frictions are lower in good times, this option value lessens in good times and so good times generate a flow of individuals into $N$. Once again, matching this feature of the data emphasizes the importance of modeling heterogeneity; it is exactly those individuals who are currently employed but who do not benefit from employment in a static sense that are responsible for this property of the model. Another effect is the wealth effect, originating from the change in the lifetime income due to the changes in the frictions and prices. In contrast to the $f_{U N}$ case, the above effects mostly work on impact of the shock, and therefore the autocorrelation of $f_{E N}$ tends to be close to zero.

Lastly, we consider the $N$-to- $U$ and $N$-to- $E$ flows. In the model (and the data), $f_{N U}$ is countercyclical and $f_{N E}$ is procyclical. In the model, the primary source of flows from $N$ into either $U$ or $E$ is those individuals who are close to the boundary but on the $N$ side, since individuals who are far from this boundary are those who are relatively far from finding employment desirable. A small shock to individual state variables can push such an individual across the boundary and into the $U$ or $E$ regions. For an individual to flow into $U$, the individual must not simultaneously receive an acceptable employment opportunity, since this will take them from $N$ into $E$ instead of from $N$ into $U$. But during good times the increase in job opportunity arrival rates implies that marginal $N$ workers are more likely to receive offers that take them into $E$, thus decreasing the rate at which these workers flow into $U$ and increasing the rate at which these workers flow into $E$.

\section{The Relative Importance of the Three Shocks}

The previous section showed that a model that features shocks to both aggregate TFP and frictions can do a good job of accounting for business cycle fluctuations in the labor market, not only in terms of the behavior of the stocks, but also in terms of the gross flows. In this section we assess the relative importance of the three key shocks in our model. 


\subsection{Decomposition Results}

Because the three $\lambda_{j}$ 's all move proportionately over the business cycle in our calibration, we decompose the fluctuations into three sources: those due to fluctuations in aggregate TFP $(Z)$, those due to fluctuations in the job-separation rate $(\phi)$, and those due to fluctuations in the vector of employment arrival rates (the three $\lambda_{j}$ 's). In each case we recompute the equilibrium assuming that only one of the shock variances is positive, with the other two set to zero. Table 11 presents results for the cyclical properties of the stocks.

Table 11

\begin{tabular}{c|ccc|ccc|ccc}
\hline \hline \multicolumn{10}{c}{ Cyclical Behavior of Stocks: Shock Decomposition } \\
\hline & \multicolumn{3}{c|}{ TFP Shocks } & \multicolumn{1}{c}{ Job-Finding Rate Shocks } & \multicolumn{3}{c}{ Separation Rate Shocks } \\
\hline \multirow{3}{*}{$\operatorname{std}(x)$} & $u$ & lfpr & $E$ & $u$ & $l f p r$ & $E$ & $u$ & lfpr & $E$ \\
$\operatorname{corrcoef}(x, Y)$ & 0.008 & 0.0042 & 0.0026 & 0.099 & 0.0020 & 0.0053 & 0.037 & 0.0006 & 0.0023 \\
$\operatorname{corrcoef}\left(x, x_{-1}\right)$ & 0.11 & 0.96 & 0.94 & -0.96 & -0.43 & 0.99 & -0.95 & -0.75 & 0.97 \\
\hline \hline
\end{tabular}

A few messages emerge. We begin with the fluctuations in employment. While all three shocks generate highly procyclical and persistent fluctuations in employment, the most important shock is the shock to the job-finding rate; it generates fluctuations that are about twice as large as those due to fluctuations in either TFP or the separation rate. Shocks to TFP and to the separation rate are about equally important in generating fluctuations in employment. Put somewhat differently, although TFP shocks are a significant source of fluctuations in aggregate employment, they are not the dominant source of those fluctuations.

Next consider the fluctuations in the unemployment rate. Both the job finding rate shocks and the separation rate shocks generate persistent countercyclical fluctuations in the unemployment rate, with the job-finding rate shocks generating fluctuations in $u$ that are almost three times as large. Consistent with the results from earlier, TFP shocks alone generate fluctuations in $u$ that are relatively small, relatively acyclical, and moderately persistent. Put somewhat differently, fluctuations in the unemployment rate are driven almost exclusively by shocks to the frictional parameters. 
Lastly, we turn to the fluctuations in the labor force participation rate. The role of shocks to frictions largely mimics the results for fluctuations in the unemployment rate. Shocks to both the job-finding rate and the separation rate generate fluctuations in the participation rate that are countercyclical and relatively persistent, and shocks to the job-finding rate generate fluctuations that are roughly three times as large as those due to shocks to the jobseparation rate. And again consistent with earlier results, shocks to TFP generate persistent procyclical movements in the participation rate, and quantitatively, the fluctuations due to TFP shocks are roughly twice as large as those due to fluctuations in the job-finding rate.

Table 12 repeats the previous analysis, but this time reporting the statistics for the fluctuations in the gross flows. For ease of comparison the top two panels also include the counterparts from the data.

Table 12

\begin{tabular}{|c|c|c|c|c|c|c|}
\hline \multicolumn{7}{|c|}{ Cyclical Behavior of Gross Worker Flows: Shock Decomposition } \\
\hline \multicolumn{7}{|c|}{ A. AZ-Adjusted Data } \\
\hline & $f_{E U}$ & $f_{E N}$ & $f_{U E}$ & $f_{U N}$ & $f_{N E}$ & $f_{N U}$ \\
\hline $\operatorname{std}(x)$ & 0.089 & 0.083 & 0.088 & 0.106 & 0.103 & 0.072 \\
\hline $\operatorname{corrcoef}(x, Y)$ & -0.63 & 0.43 & 0.76 & 0.61 & 0.52 & -0.23 \\
\hline $\operatorname{corrcoef}\left(x, x_{-1}\right)$ & 0.59 & 0.29 & 0.75 & 0.62 & 0.38 & 0.30 \\
\hline \multicolumn{7}{|c|}{ B. DeNUNified Data } \\
\hline & $f_{E U}$ & $f_{E N}$ & $f_{U E}$ & $f_{U N}$ & $f_{N E}$ & $f_{N U}$ \\
\hline $\operatorname{std}(x)$ & 0.069 & 0.036 & 0.076 & 0.066 & 0.042 & 0.063 \\
\hline $\operatorname{corrcoef}(x, Y)$ & -0.66 & 0.29 & 0.81 & 0.55 & 0.57 & -0.56 \\
\hline $\operatorname{corrcoe} f\left(x, x_{-1}\right)$ & 0.70 & 0.22 & 0.85 & 0.58 & 0.48 & 0.57 \\
\hline \multicolumn{7}{|c|}{ C. TFP Shocks } \\
\hline & $f_{E U}$ & $f_{E N}$ & $f_{U E}$ & $f_{U N}$ & $f_{N E}$ & $f_{N U}$ \\
\hline $\operatorname{std}(x)$ & 0.004 & 0.028 & 0.001 & 0.019 & 0.016 & 0.022 \\
\hline $\operatorname{corr}(x, Y)$ & 0.88 & -0.46 & 0.49 & -0.69 & 0.43 & -0.05 \\
\hline $\operatorname{corr}\left(x, x_{-1}\right)$ & 0.68 & 0.24 & 0.68 & 0.66 & 0.51 & 0.34 \\
\hline \multicolumn{7}{|c|}{ D. Job-Finding Rate Shocks } \\
\hline & $f_{E U}$ & $f_{E N}$ & $f_{U E}$ & $f_{U N}$ & $f_{N E}$ & $f_{N U}$ \\
\hline $\operatorname{std}(x)$ & 0.029 & 0.055 & 0.089 & 0.028 & 0.050 & 0.085 \\
\hline $\operatorname{corr}(x, Y)$ & -0.80 & 0.09 & 0.78 & 0.02 & 0.64 & -0.92 \\
\hline $\operatorname{corr}\left(x, x_{-1}\right)$ & 0.81 & 0.09 & 0.80 & 0.57 & 0.72 & 0.88 \\
\hline \multicolumn{7}{|c|}{ E. Job-Separation Rate Shocks } \\
\hline & $f_{E U}$ & $f_{E N}$ & $f_{U E}$ & $f_{U N}$ & $f_{N E}$ & $f_{N U}$ \\
\hline $\operatorname{std}(x)$ & 0.063 & 0.010 & 0.001 & 0.031 & 0.007 & 0.005 \\
\hline $\operatorname{corr}(x, Y)$ & -0.80 & -0.73 & -0.92 & 0.98 & -0.74 & -0.85 \\
\hline $\operatorname{corr}\left(x, x_{-1}\right)$ & 0.80 & 0.23 & 0.87 & 0.89 & 0.75 & 0.83 \\
\hline
\end{tabular}


There is a lot of information in this table, and here we highlight just a few patterns of interest. First, we have previously assessed the ability of TFP shocks to generate the observed cyclical patterns in the gross flows and noted that they generate counterfactual cyclicality for four of the six flows. In particular, TFP shocks do not account for the somewhat counterintuitive cyclicality of $f_{E N}$ and $f_{U N}$. Moreover, in our calibrated model, we see that TFP shocks contribute virtually nothing to explaining the volatility of flows between $E$ and $U$.

Shocks to the job-finding rate generate fluctuations in the gross flows that replicate the cyclicality patterns in the data, though the two flows into non-participation- $f_{E N}$ and $f_{U N}-$ are effectively acyclical in the model. Moreover, the magnitude of the fluctuations in each of the gross flows is significant in comparison to the values in the data. Note that even though $\phi$ is held constant in this exercise, shocks to the job-finding rate generate sizeable countercyclical fluctuations in $f_{E U}$. This is explained by time aggregation: when job-finding rates are high, it is more likely that an employed worker who suffers a separation shock will immediately find employment and so not show up in the data as a flow from $E$ to $U$. This same element of time aggregation is implicit in the CPS, and as we noted earlier, we did not correct the data for time aggregation on account of the fact that our model implicitly features time aggregation.

Shocks to the job-separation rate tend to have significant impacts on only a few flows. Not surprisingly, they have a very large impact on the behavior of $f_{E U}$ by directly impacting the separation rate. We also see that these shocks are particularly important for the behavior of $f_{U N}$, one of the flows that we have identified as displaying counterintuitive cyclical patterns. This is related to our earlier discussion of composition effects: when $\phi$ is small, fewer employed people experience separations, so both employment and output tend to be higher. Because fewer employed individuals experience separations, fewer individuals in the unemployment pool are there because of separations from employment. Those in the unemployment pool 
are therefore more likely to be marginally attached to the labor force and hence are more likely to transition to out of the labor force.

\subsection{Discussion}

Summarizing the previous analysis of the labor market stocks, our decomposition exercise leads to a simple picture of labor market fluctuations. As noted earlier, fluctuations in the labor market are to a first approximation largely accounted for by equal and opposite movements in employment and unemployment. In our model, this dynamic is driven solely by shocks to frictions. Moreover, shocks to the job-finding rate are about three times as important as shocks to the job-separation rate. However, if one abstracts from TFP shocks, the resulting fluctuations in employment will be only about three quarters as large as in the data, and this TFP driven component of employment fluctuations is driven by procyclical movements in participation. Absent shocks to TFP, the labor force participation rate would be markedly countercyclical, in contrast to the data. As we detail more in the next section, this is the result of general equilibrium forces.

We close this section by highlighting a more subtle interpretation of our results concerning the importance of TFP shocks. In the preceding decomposition analysis, we have treated shocks to frictions and TFP as separate exogenous shocks. But labor market models in the tradition of Mortensen and Pissarides (1994) have the implication that shocks to TFP will generate fluctuations in the job-finding rate and the job separation rate endogenously. An open question in the literature is what primitive shocks can account for the fluctuations in these values that summarize labor market frictions. To the extent that fluctuations in labor market frictions are due to fluctuations in TFP, our results do not imply that TFP shocks are not an important source of labor market fluctuations.

However, even if this is the case, our results still have an important message regarding the mechanisms through which TFP shocks affect labor market outcomes. In particular, traditional RBC analyses focused on TFP shocks as the sole driving force and also assumed 
that the sole mechanism through which TFP shocks lead to labor market fluctuations is by affecting prices that in turn generate labor supply responses. In particular, in our calibrated economy that closely matches the salient quantitative features of labor market fluctuations, labor supply effects generated by TFP induced price changes alone account for only about one quarter of employment fluctuations. That is, even if TFP shocks are responsible for all of employment fluctuations, the mechanism that traditional RBC studies focused on is not the dominant mechanism at work.

\section{Partial vs General Equilibrium}

A important cornerstone of the original RBC literature was the insistence on analyzing business cycles in the context of general equilibrium. One of the contributions of our analysis in this paper relative to that in Krusell et al. (2017) is to extend it to general equilibrium. In this section we highlight how the extension to general equilibrium matters for some of the results.

A key finding from the partial equilibrium analysis of Krusell et al. (2017) was that a model that featured only shocks to frictions could do a good job of accounting for the cyclical behavior of labor market stocks and gross flows. Importantly, this analysis held $w$ and $r$ fixed. In the previous sections of this paper we have noted that a model without TFP shocks, i.e., a model with only shocks to frictions, could not account for all of the salient features of the data. In particular, as noted at the end of the previous section, a key dimension along which a model with only shocks to frictions fails to match the data is that of the procyclicality of the participation rate. Absent shocks to TFP, our model predicts strongly countercyclical movements in the participation rate.

General equilibrium effects are completely responsible for this different finding. To see why, we note that in Krusell et al. (2017), the reason that shocks to frictions could generate procyclical movements in participation was that higher job-finding rates (also the rate of 
receiving job offers while on the job) and lower job-separation rates implied that workers could find employment and climb the job ladder more quickly, effectively increasing the return to market work even if the wage per efficiency unit of labor $(w)$ was fixed. However, general equilibrium effects work to offset this effect. If higher job-finding rates and lower job-separation rates lead to an increase in participation, they will also lead to an increase in employment.

Holding TFP constant, and realizing that the capital stock will only respond slowly, the increase in employment will decrease the effective capital to labor ratio, thereby decreasing the marginal product of a unit of labor and, in general equilibrium, decreasing the wage. This wage in turn will decrease the incentive for individuals to participate. In our calibrated economy, this general equilibrium effect dominates, and shocks to frictions alone lead to strongly countercyclical movements in participation.

To shed additional light on this, we now present the results that would emerge from a partial equilibrium analysis of our model in which there are only shocks to frictions. In particular, we keep the values of $r, w$, and $T$ fixed at their steady state levels and calibrate the friction shocks using the same procedure as earlier. That is, we target the fluctuations in $f_{E U}$ and $f_{U E}$.

Table 13 shows the implied magnitudes for the shocks. While calibrating the shocks in partial equilibrium yields slightly different values, the differences are quite small relative to those reported in Table 8.

\section{Table 13}

\begin{tabular}{cc}
\hline \hline \multicolumn{2}{c}{ Calibration of Shocks } \\
\hline$\sigma_{\lambda}$ & $\sigma_{\phi}$ \\
0.044 & 0.029 \\
\hline \hline
\end{tabular}


Table 14

\begin{tabular}{c|ccc|ccc}
\hline \hline \multicolumn{6}{c}{ Cyclical Behavior of Stocks: Partial Equilibrium With Friction Shocks } \\
\hline & \multicolumn{3}{|c|}{ Data } & \multicolumn{3}{c}{ Model } \\
\hline & $u$ & lfpr & $E$ & $u$ & $l f p r$ & $E$ \\
$\operatorname{std}(x)$ & 0.117 & 0.0026 & 0.0099 & 0.131 & 0.0024 & 0.0095 \\
$\operatorname{corrcoef}(x, Y)$ & -0.84 & 0.21 & 0.83 & -0.97 & 0.32 & 0.999 \\
$\operatorname{corrcoef}\left(x, x_{-1}\right)$ & 0.93 & 0.69 & 0.92 & 0.89 & 0.66 & 0.90 \\
\hline \hline
\end{tabular}

Table 14 shows the results for the cyclical behavior of the stocks. ${ }^{23}$ In contrast to our earlier findings, a model with only shocks to frictions is seen to do a very good job of capturing the properties of fluctuations in all three stocks. In particular, despite the fact that there are no shocks to TFP, we see that the magnitude of fluctuations in employment are very close to those in the data, and that both the volatility and cyclicality of the participation rate are closely in line with those in the data.

Table 15

\begin{tabular}{ccccccc}
\hline \hline \multicolumn{6}{c}{ Cyclical Behavior of Gross Worker Flows: } & Partial Equilibrium With Friction Shocks \\
\hline & $f_{E U}$ & $f_{E N}$ & $f_{U E}$ & $f_{U N}$ & $f_{N E}$ & $f_{N U}$ \\
\hline $\operatorname{std}(x)$ & 0.089 & 0.043 & 0.088 & 0.054 & 0.041 & 0.044 \\
$\operatorname{corr}(x, Y)$ & -0.85 & -0.17 & 0.81 & 0.97 & 0.71 & -0.98 \\
$\operatorname{corr}\left(x, x_{-1}\right)$ & 0.82 & -0.13 & 0.79 & 0.81 & 0.73 & 0.91 \\
\hline \hline
\end{tabular}

Table 15 shows the results for the fluctuations in the gross flows. The main message from this table is that the partial equilibrium analysis with only shocks to frictions can also match the key features of the fluctuations in the gross flows. The model generates the incorrect sign for the cyclicality of $f_{E N}$, but the extent of the mismatch seems relatively minor: in the data this flow is very modestly procyclical, while in the model it is very modestly countercyclical.

The above calculations indicate that general equilibrium considerations play an important role in inference regarding the importance of different shocks and the impact of particular shocks. To better highlight this, we now repeat the analysis that assumes only shocks to frictions, but this time the analysis is carried out in general equilibrium. Calibrating the magnitude of the frictions shocks to target fluctuations in $f_{E U}$ and $f_{U E}$ as before, we obtain

\footnotetext{
${ }^{23}$ Because this analysis is partial equilibrium it does not actually generate a series for output. In order to report a value for the correlation with output we impute output using the Cobb Douglas production function used to calibrate the steady state and vary $L$ according to the model holding $K$ and $Z$ fixed. This makes movements in employment very highly correlated with output, as seen in the results below.
} 
shock magnitudes as indicated in Table 16. Once again we see that calibrating them in general equilibrium has a small effect. ${ }^{24}$

Table 16

\begin{tabular}{cc}
\hline \hline \multicolumn{2}{c}{ Calibration of Shocks } \\
\hline$\sigma_{\lambda}$ & $\sigma_{\phi}$ \\
0.042 & 0.029 \\
\hline \hline
\end{tabular}

Table 17

\begin{tabular}{c|ccc|ccc}
\hline \hline \multicolumn{6}{c}{ Cyclical Behavior of Stocks: General Equilibrium With Only Friction Shocks } \\
\hline & \multicolumn{3}{c|}{ Data } & \multicolumn{3}{c}{ Model } \\
\hline & $u$ & $l f p r$ & $E$ & $u$ & lfpr & $E$ \\
$\operatorname{std}(x)$ & 0.117 & 0.0026 & 0.0099 & 0.134 & 0.0025 & 0.0075 \\
$\operatorname{corrcoef}(x, Y)$ & -0.84 & 0.21 & 0.83 & -0.96 & -0.52 & 0.99 \\
$\operatorname{corrcoef}\left(x, x_{-1}\right)$ & 0.93 & 0.69 & 0.92 & 0.89 & 0.65 & 0.89 \\
\hline \hline
\end{tabular}

Table 17 shows the implications for the fluctuations in the stocks. Consistent with our earlier analysis, we see that this specification misses an important fraction of fluctuations in employment, and that it generates a strong countercylical pattern for the participation rate. For completeness, Table 18 shows the results for the gross flows. The impact of general equilibrium on the flows is somewhat more subtle, but we would highlight the fact that the volatility of $f_{N U}$ is much higher in the general equilibrium exercise, and that since this flow is countercyclical it serves to make participation countercyclical.

Table 18

\begin{tabular}{ccccccc}
\hline \hline \multicolumn{6}{c}{ Cyclical Behavior of Gross Worker Flows: } & General Equilibrium With Only Friction Shocks \\
\hline & $f_{E U}$ & $f_{E N}$ & $f_{U E}$ & $f_{U N}$ & $f_{N E}$ & $f_{N U}$ \\
\hline $\operatorname{std}(x)$ & 0.089 & 0.059 & 0.088 & 0.032 & 0.044 & 0.089 \\
$\operatorname{corr}(x, Y)$ & -0.80 & -0.02 & 0.78 & 0.92 & 0.62 & -0.92 \\
$\operatorname{corr}\left(x, x_{-1}\right)$ & 0.81 & 0.02 & 0.80 & 0.80 & 0.72 & 0.88 \\
\hline \hline
\end{tabular}

\section{Conclusion}

An important challenge in the early RBC literature was to develop a model in which TFPinduced changes in prices would lead to sufficiently large fluctuations in labor supply to account for the large fluctuations in employment that we observe in the data. Hansen (1985)

\footnotetext{
${ }^{24}$ A general equilibrium model with rigid real wages could also be considered; we conjecture that its properties would be similar to those in the partial equilibrium setting studied above.
} 
was an early example of a paper that made substantial progress toward this goal. In this paper we offer an updated perspective on the issue of accounting for labor market fluctuations. Our perspective stresses two features relative to the early RBC literature. First, a good model should account not only for the fluctuations in aggregate employment, but also for the fluctuations in unemployment and participation. Second, in addition to accounting for the fluctuations in these aggregate statistics, a good model of labor market fluctuations should also account for the movements of individuals that generate these movements in aggregate stocks.

We have developed a version of the growth model that can successfully account for these features of the data when subjected to shocks in TFP and labor market frictions. A key finding from our analysis is that while TFP-induced price changes are a significant part of the overall story, they are not the dominant mechanism. Instead, shocks to the parameters that characterize labor market frictions and the effects that these generate are the dominant mechanism at work. We also find that general equilibrium effects are important for our conclusions about the driving forces behind labor market fluctuations.

We close by highlighting two broad directions for future work. First, while our model is successful in accounting for many qualitative and quantitative features of the data, there is still scope for improvement along some dimensions. For example, in our benchmark calibration the labor force participation rate displays more cyclicality than is found in the data. As noted earlier, the relative importance of TFP shocks is a key source of this discrepancy. We conjecture that considering additional shocks (e.g., cyclical variation in UI or other social insurance programs) or additional propagation mechanisms (e.g., sticky wages) may help with this.

Second, in this paper we have viewed the frictional labor market parameters as technological features of the environment. One possibility is that the movements in labor market frictions that our model requires to match the data can be understood as the endogenous 
response to the movements in TFP that our model requires. A large literature has worked in this issue in the context of somewhat simpler models; see, for example the early contributions of Shimer (2005), Hall (2005), and Hagedorn and Manovskii (2008). Extending these earlier analyses that abstracted from participation decisions to our setting seems an important issue for future research in this area. 


\section{References}

[1] Abowd, J., and A. Zellner (1985). "Estimating Gross Labor-Force Flows," Journal of Business and Economic Statistics 3, 254-283.

[2] Alvarez, F., and R. Shimer (2011). "Search and Rest Unemployment," Econometrica 79, $75-122$.

[3] Alvarez, F. and M. Veracierto (2000). "Labor-Market Policies in an Equilibrium Search Model," NBER Macroeconomics Annual 1999, edited by B. S. Bernanke and J. J. Rotemberg, MIT Press.

[4] Blanchard, O., and P. Diamond (1990), "The Cyclical Behavior of the Gross Flows of U.S. Workers," Brookings Papers on Economic Activity, 85-155.

[5] Boppart, T., P. Krusell, and K. Mitman (2018). "Exploiting MIT Shocks in Heterogeneous-Agent Economies: the Impulse Response as a Numerical Derivative," Journal of Economic Dynamics and Control 89, 68-92.

[6] Card, D. (1994). "Intertemporal Labor Supply: An Assessment," in Advances in Econometrics, edited by Chris Sims, Cambridge University Press, 49-81.

[7] Chang, Y., and S. Kim. (2006). "From Individual to Aggregate Labor Supply: A Quantitative Analysis Based on a Heterogeneous Agent Macroeconomy," International Economic Review 47, 1-27.

[8] Christiano, L., M. Trabandt, and K. Walentin (2010). "Involuntary Unemployment and the Business Cycle," mimeo.

[9] Chua, T. C. and W. A. Fuller (1987). "A Model for Multinomial Response Error Applier to Labor Flows," Journal of the American Statistical Association 82, 46-51. 
[10] Cooley, T. F. ed. (1995). Frontiers of Business Cycle Research, Princeton University Press.

[11] Davis, S.J. and J. Haltiwanger (1992). "Gross Job Creation, Gross Job Destruction, and Employment Reallocation," Quarterly Journal of Economics 107, 819-863.

[12] Ebell, M. (2011). "On the Cyclicality of Unemployment: Resurrecting the Participation Margin," Labour Economics 18, 822-836.

[13] Elsby, M., B. Hobijn, and A. Şahin (2015). "On the Importance of the Participation Margin for Labor Market Fluctuations," Journal of Monetary Economics 72, 64-82.

[14] Fallick, B., and C. A. Fleischman (2004). "Employer-to-Employer Flows in the U.S. Labor Market: The Complete Picture of Gross Worker Flows," Finance and Economics Discussion Series 2004-34. Board of Governors of the Federal Reserve System.

[15] Floden, M., and J. Linde (2001). "Idiosyncratic Risk in the United States and Sweden: Is There a Role for Government Insurance?" Review of Economic Dynamics 4, 406-437.

[16] French, E. (2005). "The Effect of Health, Wealth and Wages on Labour Supply and Retirement Behavior," Review of Economic Studies 72, 395-427.

[17] Fujita, S., and G. Ramey (2009). "The Cyclicality of Separation and Job-Finding Rates," International Economic Review 2, 415-430.

[18] Galí, J., F. Smets, and R. Wouters (2011). "Unemployment in an Estimated New Keynesian Model," mimeo.

[19] Garibaldi, P. and E. Wasmer (2005). "Equilibrium Search Unemployment, Endogenous Participation, and Labor Market Flows," Journal of European Economic Association 3, $851-882$. 
[20] Golosov, M. and R. E. Lucas Jr., (2007). "Menu Costs and Phillips Curves," Journal of Political Economy, 115, 171-199.

[21] Haefke, C. and M. Reiter (2011). "What Do Participation Fluctuations Tell Us About Labor Supply Elasticities?" mimeo, IZA.

[22] Hagedorn, M. and I. Manovskii (2008). "The Cyclical Behavior of Equilibrium Unemployment and Vacancies Revisited," American Economic Review 98, 1692-1706.

[23] Hall, R. (2005). "Employment Fluctuations with Equilibrium Wage Stickiness," American Economic Review 95, 50-65.

[24] Ham, J. (1982). "Estimation of a Labour Supply Model with Censoring due to Unemployment and Underemployment," Review of Economic Studies 49, 335-354.

[25] Hansen, G. (1985). "Indivisible Labor and the Business Cycle," Journal of Monetary Economics 16, 309-337.

[26] Kaplan G, and and G. Violante (2014). "Model of the Consumption Response to Fiscal Stimulus Payments " Econometrica 82, 1199-1239.

[27] Krueger, D., F. Perri, L. Pistaferri, and G. L. Violante (2010). "Cross-Sectional Facts for Macroeconomists, " Review of Economic Dynamics 13, 1-14.

[28] Krusell, P., T. Mukoyama, R. Rogerson, and A. Şahin (2011). "A Three State Model of Worker Flows in General Equilibrium, ” Journal of Economic Theory 146, 1107-1133.

[29] Krusell, P., T. Mukoyama, R. Rogerson, and A. Şahin (2012). "Is Labor Supply Important for Business Cycles?" NBER Working Paper 17779.

[30] Krusell, P., T. Mukoyama, R. Rogerson, and A. Şahin (2017). "Gross Worker Flows Over the Business Cycle" American Economic Review 107, 3447-3476. 
[31] Krusell, P., and A. Smith Jr. (1998). "Income and Wealth Heterogeneity in the Macroeconomy," Journal of Political Economy 106, 867-896.

[32] Low, A., C. Meghir, and L. Pistaferri (2010). "Wage Risk and Employment Risk over the Life Cycle," American Economic Review 100, 1432-1467.

[33] Lucas, R. E., and E. Prescott (1974). "Equilibrium search and unemployment," Journal of Economic Theory 7, 188-209.

[34] Mendoza, E., A. Razin, and L. Tesar (1994). "Effective Tax Rates in Macroeconomics: Cross-Country Estimates of Tax Rates on Factor Incomes and Consumption," Journal of Monetary Economics 34, 297-323.

[35] Mortensen, D. T. and C. A. Pissarides (1994). "Job Creation and Job Destruction in the Theory of Unemployment," Review of Economic Studies 61, 397-415.

[36] Mukoyama, T. (2013). "Understanding the Welfare Effects of Unemployment Insurance Policy in General Equilibrium," Journal of Macroeconomics 38, 347-368.

[37] Mukoyama, T., Patterson C. and A. Şahin (2018). "Job Search Behavior over the Business Cycle," American Economic Journal: Macroeconomics 11, 190-215.

[38] Poterba, J., and L. Summers (1986). "Reporting Errors and Labor Market Dynamics," Econometrica 54, 1319-1338.

[39] Rogerson, R. (1988). "Indivisible Labor, Lotteries and Equilibrium," Journal of Monetary Economics 21, 3-16.

[40] Rogerson, R., R. Shimer and R. Wright (2005). "Search-Theoretic Models of the Labor Market: A Survey," Journal of Economic Literature 43, 959-988.

[41] Shimer, R. (2005). "The Cyclical Behavior of Equilibrium Unemployment and Vacancies," American Economic Review 95, 25-49. 
[42] Shimer, R. (2012). "Reassessing the Ins and Outs of Unemployment," Review of Economic Dynamics 15, 127-148.

[43] Shimer, R. (2013). "Job Search, Labor-Force Participation, and Wage Rigidities" Advances in Economics and Econometrics: Theory and Applications, Tenth World Congress, Volume II, Chapter 5, edited by D. Acemoglu, M. Arellano, and E. Dekel, Cambridge University Press.

[44] Thomas J. (2002). "Is Lumpy Investment Relevant for the Business Cycle?" Journal of Political Economy 110, 508-534.

[45] Tjaden, V. and F. Wellschmied (2014). "Quantifying the Contribution of Search to Wage Inequality," American Economic Journal: Macroeconomics 6, 134-161.

[46] Tripier, F. (2004). "Can the Labor Market Search Model Explain the Fluctuations of Allocations of Time?" Economic Modelling 21, 131-146.

[47] Veracierto, M. (2002). "Plant Level Irreversible Investment and Equilibrium Business Cycles," American Economic Review 92, 181-97.

[48] Veracierto, M. (2008). "On the Cyclical Behavior of Employment, Unemployment and Labor Force Participation," Journal of Monetary Economics 55, 1143-1157.

\section{Additional References for Appendix}

[49] Tauchen, G. (1986). "Finite State Markov-Chain Approximations to Univariate and Vector Autoregressions," Economics Letters 20, 177-181. 


\section{Appendix}

\section{A Steady State Computation}

The computation of the steady state model is conducted in the following steps.

1. Guess the steady state level of $K / L$ (which determines $w$ and $r$ ), $T$, and the average wage.

2. Perform the optimization of the workers.

3. Compute the invariant distribution of the workers over the individual state variables.

4. Compute $K / L, T$, and the average wage that are implied by the invariant distribution, and compare with the earlier guess. If they do not coincide, revise the guess and repeat from Step 2 until convergence.

For the worker optimization (Step 2), we set 50 uneven grids (more grids closer to zero) over individual capital stock (from $a=0$ to $a=5000$ ), 20 grids on $z$, and 7 grids on $q$. Stochastic processes for both $z$ and $q$ are discretized using Tauchen's (1986) method (the ranges of the grids are set at two unconditional standard deviations). We have converted the annual $\mathrm{AR}(1)$ process into a monthly $\mathrm{AR}(1)$ process using the formula analogous to the ones in Chang and Kim's (2006) Appendix A.2. In the optimization, we have allowed for choosing off-grid values of $a_{t+1}$ by linearly interpolating the value functions across the grids.

For the computation of the invariant distribution, we represent the distribution of workers in terms of the "density" (i.e., how many people are at each state) over the state variables $(a, z)$ in addition to employment status. For employed workers, $q$ is an additional state variable. We iterate on the density using the decision rules that were derived in Step 2 and the Markov transition matrices for the stochastic processes until it converges to an invariant density. In the a dimension, we have used a finer set of grids (300 grids) instead of the original 50 grids in calculating the density. (The decision rules are linearly interpolated.) 


\section{B Business Cycle Computation}

The method developed by Boppart et al. (2018) consists of two key components. First, the response of the economy to an unanticipated deviation (Boppart et al. (2018) call it an "MIT shock") of one parameter and its gradual transition back to the original steady state is computed as a deterministic transition path. Note that only one parameter (in the case of $\lambda$, $\left(\lambda_{u}, \lambda_{n}, \lambda_{e}\right)$ together) is changed in computing this transition path. We assume, for example, $Z_{t}$ follows

$$
\log \left(Z_{t+1}\right)=\rho \log \left(Z_{t}\right)
$$

where $\rho \in(0,1)$ is the persistence parameter and $t=0,1,2, \ldots$. The initial deviation $Z_{0}$ is set at

$$
Z_{0}=\exp \left(\epsilon_{Z}\right)
$$

where $\epsilon_{Z}$ is the size of deviation. Similarly, the transition path from the deviation of $\lambda_{u}$ is computed assuming

$$
\log \left(\lambda_{u, t+1}\right)-\log \left(\bar{\lambda}_{u}\right)=\rho\left(\log \left(\lambda_{u, t}\right)-\log \left(\bar{\lambda}_{u}\right)\right)
$$

for $t=0,1,2, \ldots$, where $\bar{\lambda}_{u}$ is the steady state value. This equation implies

$$
\lambda_{u, t+1}=\lambda_{u, t}^{\rho} \bar{\lambda}_{u}^{1-\rho}
$$

The initial deviation for $\lambda_{u}$ is

$$
\lambda_{u, 0}=\bar{\lambda}_{u} \exp \left(\epsilon_{\lambda}\right)
$$

We assume that $\lambda_{n}$ and $\lambda_{e}$ always move together with $\lambda_{u}$ :

$$
\frac{\lambda_{n, t}}{\lambda_{u, t}}=\frac{\bar{\lambda}_{n}}{\bar{\lambda}_{u}}
$$

and

$$
\frac{\lambda_{e, t}}{\lambda_{u, t}}=\frac{\bar{\lambda}_{e}}{\bar{\lambda}_{u}}
$$


for $t=0,1,2, \ldots$ For $\phi$, similarly

$$
\phi_{t+1}=\phi_{t}^{\rho} \bar{\phi}^{1-\rho}
$$

and the initial value for $\phi$ is

$$
\phi_{0}=\bar{\phi} \exp \left(-\epsilon_{\phi}\right)
$$

The concrete steps of this first component are as follows.

1. Compute the steady state model. Store the value functions and the stationary distribution.

2. Compute the series of $Z_{t}, \lambda_{u, t}, \lambda_{n, t}, \lambda_{e, t}$, and $\phi_{t}$ for time $0, \ldots, S$, where $S=1000$, under the above assumption.

3. Guess $K_{t} / L_{t}$ and $T_{t}$ for time $0, \ldots, S$, where $S=1000$.

4. With $K_{t} / L_{t}$, the factor prices $r_{t}$ and $w_{t}$ can be derived.

5. Based on the factor prices and $T_{t}$, perform the dynamic optimization of workers, assuming that at time $S+1$ the economy is in the steady state and moving backwards.

6. Simulate the economy from time 0 to $S$. Compute $K_{t} / L_{t}$ and $T_{t}$ from the simulation.

7. Update the guess, repeat.

Once the above is computed for three cases, we have time series for all of the outcome variables of interest (such as $E, u, l f p r$, and flow rates) for each "MIT shock". Represent one of these variables by $X$. Denote the time series of the log-deviation of $X_{\tau}$ for $\tau=0,1, \ldots, S$ (that is, $\tau$ is periods after the shock) in the case when the parameter $k$ experiences a shock (that is, $k=Z, \lambda$, or $\phi$ ) by $\bar{x}^{k, \tau}$. Then, the business cycle statistics of the outcome variable $x$ can be computed, using Monte-Carlo simulations, as follows.

1. Set the three scale parameters $\omega_{Z}, \omega_{\lambda}$, and $\omega_{\phi}$. 
2. Draw the baseline shock, $\left\{\eta_{t}\right\}$ that follows $N(0,1)$.

3. Compute the log-deviation of $X_{t}$ (call it $x$ ) as

$$
x_{t}=\sum_{k=Z, \lambda, \phi} \sum_{m=0}^{\infty} \bar{x}^{k, m} \omega_{k} \eta_{t-m} .
$$

In practice, $m$ cannot go to infinity, so we can stop the summation at $S$.

4. The value of $X_{t}$ is computed as

$$
X_{t}=\bar{X} \exp \left(x_{t}\right)
$$

where $\bar{X}$ is the steady state value of $X$. Various statistics of interest can then be computed from the simulated $X_{t}$.

The baseline shocks in the simulation are multiplied by the scale parameters, $\omega_{Z}, \omega_{\lambda}$, and $\omega_{\phi}$, which means that these scale parameters determine the magnitude of fluctuations. We determine the appropriate values of $\omega_{Z}, \omega_{\lambda}$, and $\omega_{\phi}$ by targeting statistics as described in the main text. Combining with the first step, The value of $\sigma_{k} \equiv \omega_{k} \epsilon_{k}$ determines the size of the shock to variable $k$, where $k \equiv Z, \lambda$, and $\phi$.

\section{A Case with Positive Government Expenditure}

Here, we consider the case where a part of the tax revenue is used for exogenous government spending. In the consumer's budget constraint (for the employed consumer here, but similar for nonemployed consumers)

$$
c_{t}+k_{t+1}=(1+r-\delta) k_{t}+(1-\tau) w z_{t} q_{t} e_{t}+T
$$

We assume that $T$ is now defined as

$$
T=\tau w \int z_{i} q_{i} d i-G
$$

where we set $G=0.7$ in the steady state. Given that $T=1.36$ was the equilibrium value in the benchmark, the transfer is about the half of the tax revenue. (In equilibrium, the tax 
revenue changes endogenously, and the value of $T$ in the new equilibrium is $1.32-0.7=0.62$.)

The steady state results are:

Table A1

\begin{tabular}{cccccccccccc}
\hline \hline \multicolumn{11}{c}{ Calibrated Parameter Values } \\
\hline$\beta$ & $\rho_{z}$ & $\sigma_{z}$ & $\alpha$ & $\lambda_{u}$ & $\lambda_{n}$ & $\lambda_{e}$ & $\phi$ & $\sigma_{q}$ & $\bar{\gamma}$ & $\gamma_{\min }$ & $\gamma_{\max }$ \\
0.99398 & 0.996 & 0.096 & 0.67 & 0.340 & 0.147 & 0.074 & 0.024 & 0.040 & 0.059 & 0.029 & 0.088 \\
\hline \hline
\end{tabular}

Table A2 shows the implications of our calibrated model for steady state gross worker flows. For completeness we include the corresponding values from the AZ-Adjusted data with bootstrapped confidence intervals.

Table A2

\begin{tabular}{|c|c|c|c|c|c|c|c|}
\hline \multicolumn{8}{|c|}{ Gross Worker Flows in the Data and the Model } \\
\hline \multicolumn{4}{|c|}{ AZ-Adjusted Data } & \multicolumn{4}{|c|}{ Model } \\
\hline \multirow[t]{2}{*}{ FROM } & \multicolumn{3}{|c|}{ TO } & \multirow[t]{2}{*}{ FROM } & \multicolumn{3}{|c|}{ TO } \\
\hline & $E$ & $U$ & $N$ & & $E$ & $U$ & $N$ \\
\hline$E$ & 0.972 & 0.014 & 0.014 & $E$ & 0.965 & 0.014 & 0.021 \\
\hline $95 \% \mathrm{CI}$ & $(0.970,0.974)$ & $(0.013,0.015)$ & $(0.012,0.015)$ & & & & \\
\hline$U$ & 0.228 & 0.637 & 0.135 & $U$ & 0.209 & 0.558 & 0.122 \\
\hline $95 \% \mathrm{CI}$ & $(0.211,0.246)$ & $(0.616,0.657)$ & $(0.119,0.152)$ & & & & \\
\hline$N$ & 0.022 & 0.021 & 0.957 & $N$ & 0.022 & 0.033 & 0.945 \\
\hline $95 \% \mathrm{CI}$ & $(0.019,0.025)$ & $(0.018,0.023)$ & $(0.954,0.960)$ & & & & \\
\hline
\end{tabular}

For the business cycle exercise, we keep the value of $T$ the constant at its steady state value. Shocks are calibrated as in the main text, and the parameters of the shock processes are shown in Table A3.

Table A3

\begin{tabular}{ccc}
\hline \hline \multicolumn{3}{c}{ Magnitude of Shocks } \\
\hline$\sigma_{Z}$ & $\sigma_{\lambda}$ & $\sigma_{\phi}$ \\
0.0019 & 0.050 & 0.037 \\
\hline \hline
\end{tabular}

Table A4 and A5 show the main results.

Table A4

\begin{tabular}{c|ccc|ccc}
\hline \hline \multicolumn{4}{c}{ Cyclical Behavior of Stocks With TFP and Friction Shocks } \\
\hline & \multicolumn{3}{|c|}{ Data } & \multicolumn{3}{c}{ Model } \\
\hline & $u$ & $l f p r$ & $E$ & $u$ & $l f p r$ & $E$ \\
$\operatorname{std}(x)$ & 0.117 & 0.0026 & 0.0099 & 0.120 & 0.0027 & 0.0099 \\
$\operatorname{corrcoef}(x, Y)$ & -0.84 & 0.21 & 0.83 & -0.996 & 0.48 & 0.972 \\
$\operatorname{corrcoef}\left(x, x_{-1}\right)$ & 0.93 & 0.69 & 0.92 & 0.89 & 0.67 & 0.90 \\
\hline \hline
\end{tabular}


Table A5

\begin{tabular}{|c|c|c|c|c|c|c|}
\hline \multicolumn{7}{|c|}{ Cyclical Behavior of Gross Worker Flows With TFP and Friction Shocks } \\
\hline \multicolumn{7}{|c|}{ A. AZ-Adjusted Data } \\
\hline & $f_{E U}$ & $f_{E N}$ & $f_{U E}$ & $f_{U N}$ & $f_{N E}$ & $f_{N U}$ \\
\hline $\operatorname{std}(x)$ & 0.089 & 0.083 & 0.088 & 0.106 & 0.103 & 0.072 \\
\hline $\operatorname{corrcoe} f(x, Y)$ & -0.63 & 0.43 & 0.76 & 0.61 & 0.52 & -0.23 \\
\hline $\operatorname{corrcoef}\left(x, x_{-1}\right)$ & 0.59 & 0.29 & 0.75 & 0.62 & 0.38 & 0.30 \\
\hline \multicolumn{7}{|c|}{ B. DeNUNified Data } \\
\hline & $f_{E U}$ & $f_{E N}$ & $f_{U E}$ & $f_{U N}$ & $f_{N E}$ & $f_{N U}$ \\
\hline $\operatorname{std}(x)$ & 0.069 & 0.036 & 0.076 & 0.066 & 0.042 & 0.063 \\
\hline $\operatorname{corrcoef}(x, Y)$ & -0.66 & 0.29 & 0.81 & 0.55 & 0.57 & -0.56 \\
\hline $\operatorname{corrcoef}\left(x, x_{-1}\right)$ & 0.70 & 0.22 & 0.85 & 0.58 & 0.48 & 0.57 \\
\hline \multicolumn{7}{|c|}{ C. Model } \\
\hline & $f_{E U}$ & $f_{E N}$ & $f_{U E}$ & $f_{U N}$ & $f_{N E}$ & $f_{N U}$ \\
\hline $\operatorname{std}(x)$ & 0.089 & 0.044 & 0.088 & 0.054 & 0.056 & 0.027 \\
\hline $\operatorname{corr}(x, Y)$ & -0.99 & 0.09 & 0.89 & 0.93 & 0.72 & -0.88 \\
\hline $\operatorname{corr}\left(x, x_{-1}\right)$ & 0.87 & -0.07 & 0.79 & 0.72 & 0.70 & 0.90 \\
\hline
\end{tabular}

Overall, the results are in line with the results in the main text.

\section{Targeting the DeNUNified Data}

Here, we target the fluctuations in $f_{E U}$ and $f_{U E}$ in the de $N U N$ ified data in determining the magnitude of $\lambda$ and $\phi$ shocks. As is summarized in Table A6, $\sigma_{\lambda}$ and $\sigma_{\phi}$ are significantly smaller than the calibration in the main text.

\section{Table A6}

\begin{tabular}{ccc}
\hline \hline \multicolumn{3}{c}{ Magnitude of Shocks } \\
\hline$\sigma_{Z}$ & $\sigma_{\lambda}$ & $\sigma_{\phi}$ \\
0.0101 & 0.036 & 0.023 \\
\hline \hline
\end{tabular}

Tables A7 and A8 present the main results of the business cycle exercise.

Table A7

\begin{tabular}{c|ccc|ccc}
\hline \hline \multicolumn{6}{c}{ Cyclical Behavior of Stocks With TFP and Friction Shocks } \\
\hline & \multicolumn{3}{|c|}{ Data } & \multicolumn{3}{c}{ Model } \\
\hline & $u$ & $l f p r$ & $E$ & $u$ & lfpr & $E$ \\
$\operatorname{std}(x)$ & 0.117 & 0.0026 & 0.0099 & 0.116 & 0.0046 & 0.0099 \\
$\operatorname{corrcoef}(x, Y)$ & -0.84 & 0.21 & 0.83 & -0.96 & 0.91 & 0.96 \\
$\operatorname{corrcoef}\left(x, x_{-1}\right)$ & 0.93 & 0.69 & 0.92 & 0.89 & 0.87 & 0.89 \\
\hline \hline
\end{tabular}

In this alternative calibration the participation rate is both more volatile and more procyclical than in the main text. This reflects the fact that the TFP shock is significantly larger in this specification, due to the fact that the frictional shocks are now smaller. 
Table A8

\begin{tabular}{|c|c|c|c|c|c|c|}
\hline \multicolumn{7}{|c|}{ Cyclical Behavior of Gross Worker Flows With TFP and Friction Shocks } \\
\hline \multicolumn{7}{|c|}{ A. AZ-Adjusted Data } \\
\hline & $f_{E U}$ & $f_{E N}$ & $f_{U E}$ & $f_{U N}$ & $f_{N E}$ & $f_{N U}$ \\
\hline $\operatorname{std}(x)$ & 0.089 & 0.083 & 0.088 & 0.106 & 0.103 & 0.072 \\
\hline $\operatorname{corrcoef}(x, Y)$ & -0.63 & 0.43 & 0.76 & 0.61 & 0.52 & -0.23 \\
\hline $\operatorname{corrcoef}\left(x, x_{-1}\right)$ & 0.59 & 0.29 & 0.75 & 0.62 & 0.38 & 0.30 \\
\hline \multicolumn{7}{|c|}{ B. DeNUNified Data } \\
\hline & $f_{E U}$ & $f_{E N}$ & $f_{U E}$ & $f_{U N}$ & $f_{N E}$ & $f_{N U}$ \\
\hline $\operatorname{std}(x)$ & 0.069 & 0.036 & 0.076 & 0.066 & 0.042 & 0.063 \\
\hline $\operatorname{corrcoef}(x, Y)$ & -0.66 & 0.29 & 0.81 & 0.55 & 0.57 & -0.56 \\
\hline $\operatorname{corrcoe} f\left(x, x_{-1}\right)$ & 0.70 & 0.22 & 0.85 & 0.58 & 0.48 & 0.57 \\
\hline \multicolumn{7}{|c|}{ C. Model } \\
\hline & $f_{E U}$ & $f_{E N}$ & $f_{U E}$ & $f_{U N}$ & $f_{N E}$ & $f_{N U}$ \\
\hline $\operatorname{std}(x)$ & 0.069 & 0.026 & 0.076 & 0.031 & 0.057 & 0.088 \\
\hline $\operatorname{corr}(x, Y)$ & -0.98 & 0.05 & 0.97 & -0.07 & 0.74 & -0.88 \\
\hline $\operatorname{corr}\left(x, x_{-1}\right)$ & 0.81 & -0.18 & 0.80 & 0.48 & 0.63 & 0.83 \\
\hline
\end{tabular}

Here, $f_{U N}$ is countercyclical. As is discussed in the main text, this is because the composition effect that drives the procyclicality of $f_{U N}$ in our baseline case is now weaker. 